QA: QA

TDR-EBS-MD-000017 REV 00

BECHTEL

SAIC conpew LIC

April 2001

\title{
Seismic Tomography Technology for the Water Infiltration Experiment
}

By

Jozef M. Descour, Kanaan Hanna, Dave Conover, and Bart Hoekstra

Prepared for:

U.S. Department of Energy

Yucca Mountain Site Characterization Office

P.O. Box 30307

North Las Vegas, Nevada 89036-0307

Prepared by:

Bechtel SAIC Company, LLC

1180 Town Center Drive

Las Vegas, Nevada 89144

Under Contract Number

DE-AC08-01NV12101 
QA: QA

TDR-EBS-MD-000017 REV 00

April 2001

\section{Seismic Tomography Technology for the Water Infiltration Experiment}

By Jozef M. Descour, Kanaa Hanna, Dave Conover, and Bart Hoekstra

Prepared for:

U.S. Department of Energy

Yucca Mountain Site Characterization Office

P.O. Box 30307

North Las Vegas, Nevada 89036-0307

Prepared by:

Bechtel SAIC Company, LLC

1180 Town Center Drive

Las Vegas, Nevada 89144

Under Contract Number

DE-AC08-01NV12101 


\section{DISCLAIMER}

This report was prepared as an account of work sponsored by an agency of the United States Government. Neither the United States Government nor any agency thereof, nor any of their employees, nor any of their contractors, subcontractors or their employees, makes any warranty, express or implied, or assumes any legal liability or responsibility for the accuracy, completeness, or any third party's use or the results of such use of any information, apparatus, product, or process disclosed, or represents that its use would not infringe privately owned rights. Reference herein to any specific commercial product, process, or service by trade name, trademark, manufacturer, or otherwise, does not necessarily constitute or imply its endorsement, recommendation, or favoring by the United States Government or any agency thereof or its contractors or subcontractors. The views and opinions of authors expressed herein do not necessarily state or reflect those of the United States Government or any agency thereof. 


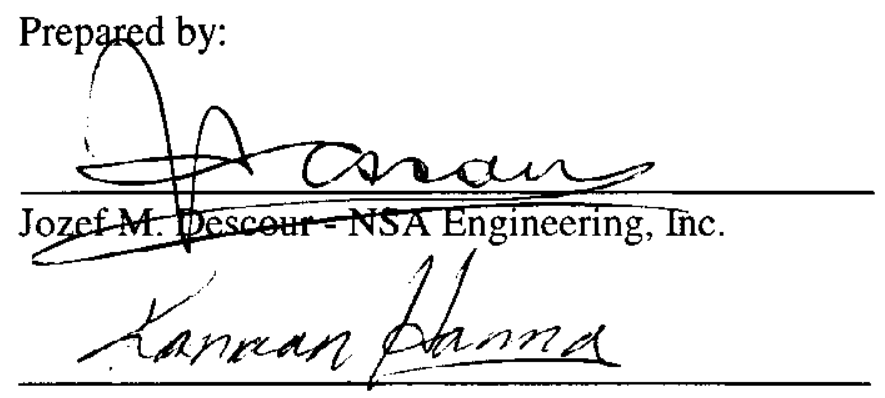

Kanaan Hanna- NSA Engineering, Inc.

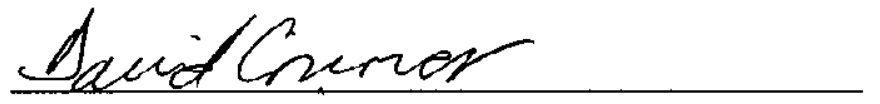

Dave Conover - NSA Engineering, Inc

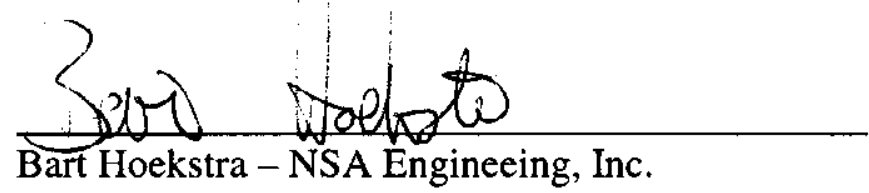

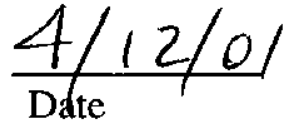

$\frac{4 / 12 / 01}{\text { Date }}$
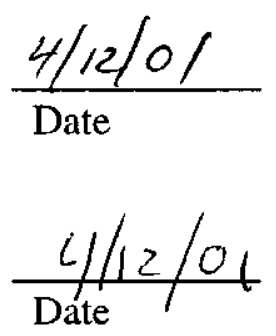

Approved by:
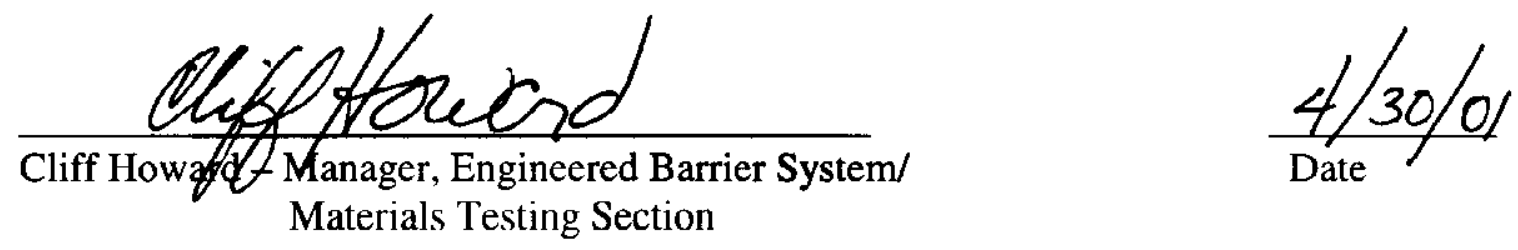

Checker Concurrence:
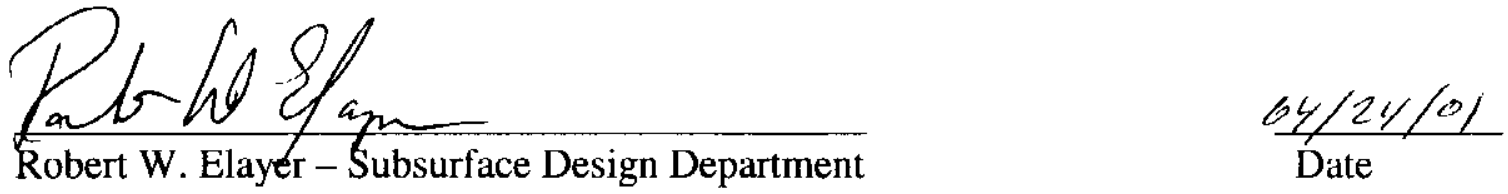
This Page Intentionally Left Blank 


\section{CONTENTS}

Page

1. OBJECTIVE AND SCOPE 1

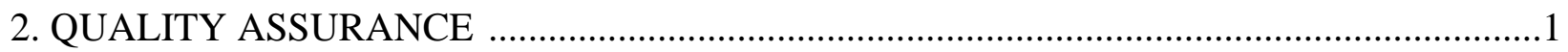

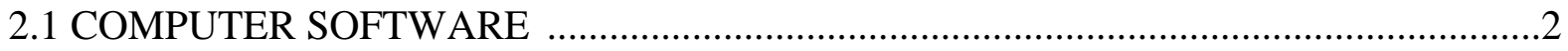

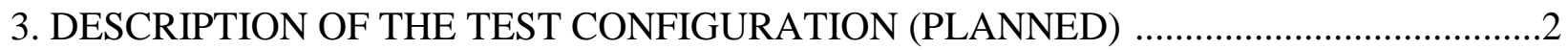

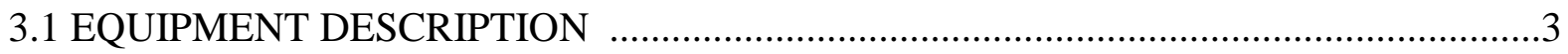

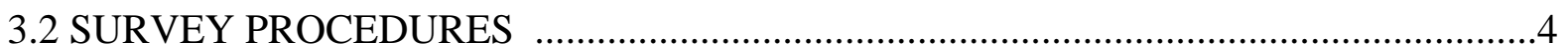

4. DESCRIPTION OF THE TEST CONFIGURATION (AS-BUILT) .....................................

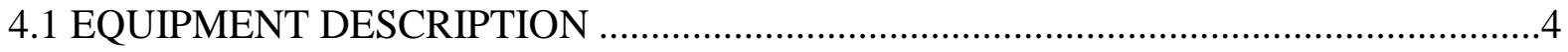

4.2 SURVEY PROCEDURES .................................................................................

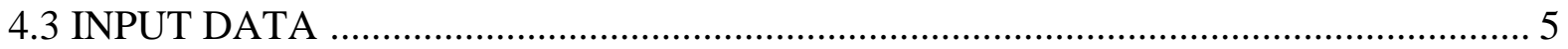

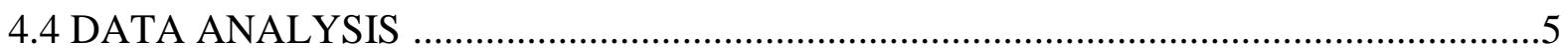

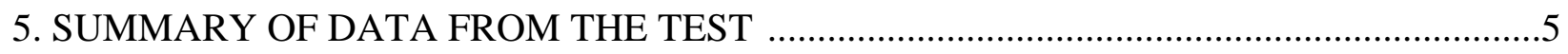

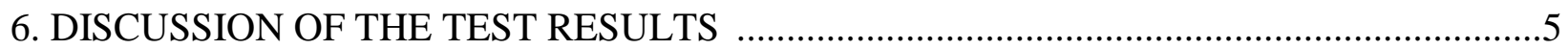

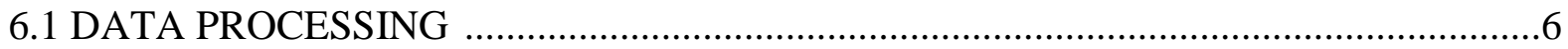

6.1.1 Evaluation of Signal Quality ……………………...........................................

6.1.2 Generation of Velocity Models and Tomograms ......................................................

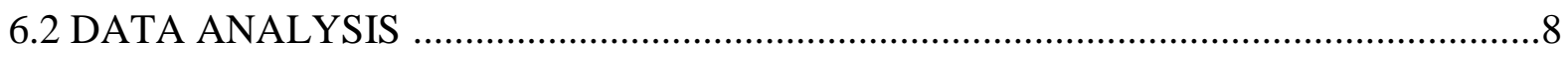

6.3 CONCLUSIONS AND RECOMMENDATIONS ......................................................

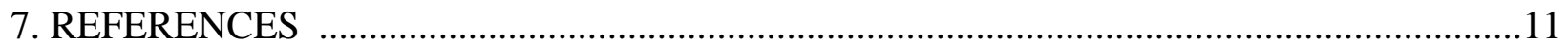

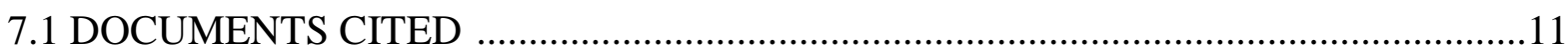

7.2 CODES, STANDARDS, REGULATIONS, AND PROCEDURES …............................12

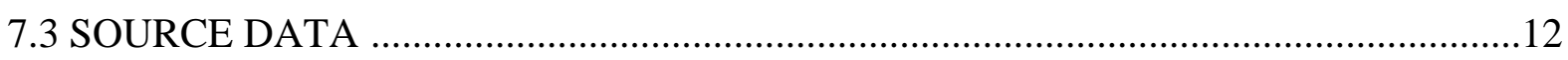

APPENDIX A - ELECTRONIC COPY OF DATA ….....................................A-1 


\section{FIGURES}

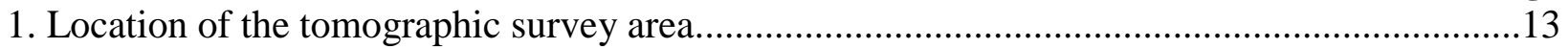

2. Three-dimensional projection of Alcove \#8 and Niche \#3 in the tomographic survey area ................................................................................................

3. Configuration of the survey holes between Alcove \#8 and Niche \#3.................................... 15

4. Plan view of Alcove \#8 Niche \#3 with borehole locations and directions ................................ 16

5. Block schematic showing components of the tomographic survey installation ........................ 17

6. Etrema magnetostrictive seismic source assembly designed for dry holes in Alcove \#8 and Niche \#3 ............................................................................ 18

7. Installation of seismic source and accelerometers-inflataphone probe assembly .....................19

8. S-wave records from Alcove \#8 and Niche \#3 using the Etreme source.................................. 20

9. P-waves and S-waves recorded from Niche \#3 using hammer strikes in Alcove \#8 ............... 21

10. Typical plots of arrival time vs. distance and P- and S-wave velocity for selected source locations .................................................................................................... 22

11. S-wave velocity contours generated without initial velocity model showing two relatively uniform rock zones above and below a transition zone........................................ 23

12. Sequence of tomograms for assessing strike azimuth, dip, and elevation of the top of the transition zone............................................................................................... 24

13. Three-dimensional representation of the initial S-wave velocity model ............................... 25

14. Ray path coverage of the tomographic survey volume within available

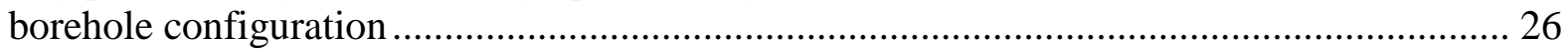

15. Refined three-dimensional S-wave velocity contours showing fractured zone between more uniform upper and lower velocity zones.............................................. 27

16. Refined S-wave velocity contours showing well-defined fractured transition zone. Green spheres represent qualitative size assessment of larger voids associated with lithophysae or fractured rock along each borehole

17. Comparison between velocity tomogram and section of the Topopah Spring Tuff showing lithologic features of the upper lithophysal zone and the middle nonlithophysal zone

18. Strike and dip of the transition zone determined by the tomographic survey in relation to the Sundance fault zone and rock foliation near the survey site ....................... 30

19. Plan view showing location of vertical slices spaced at $1 \mathrm{~m}$ apart .......................................... 31

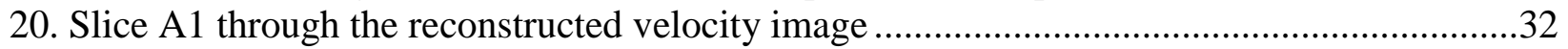

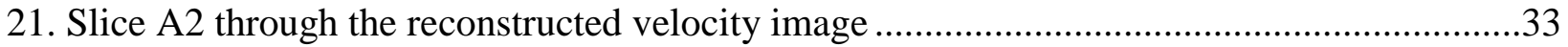

22. Slice A3 through the reconstructed velocity image .................................................................

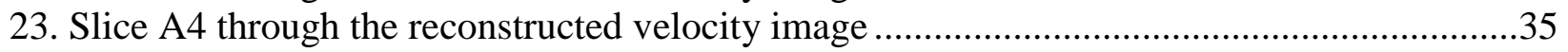

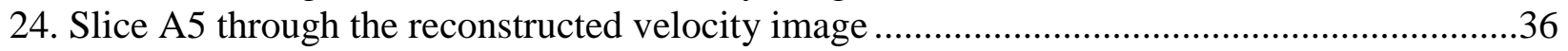

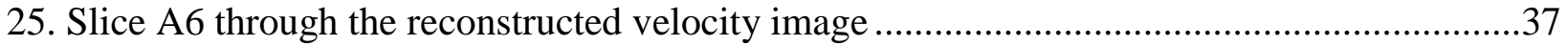

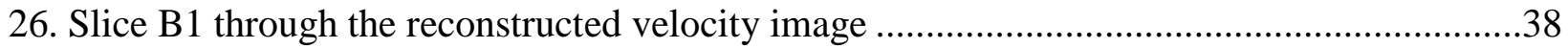

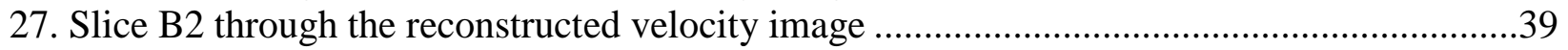

28. Slice B3 through the reconstructed velocity image ..................................................................4

29. Slice B4 through the reconstructed velocity image .............................................................4

30. Slice B5 through the reconstructed velocity image ..........................................................42

31. Slice B6 through the reconstructed velocity image .................................................................43 


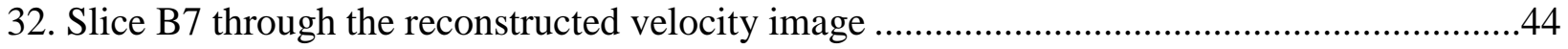

33. Slice B8 through the reconstructed velocity image ............................................................45

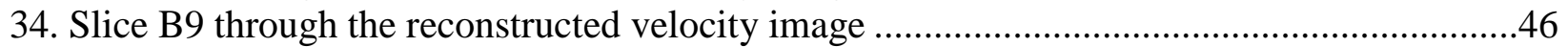

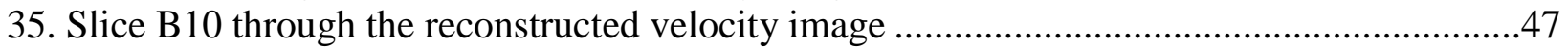




\section{LIST OF ACRONYMS}

$\begin{array}{ll}\text { AC } & \text { Alternating Current } \\ \text { CHS } & \text { Channels } \\ \text { CRWMS M\&O } & \begin{array}{l}\text { Civilian Radioactive Waste Management System Maintenance \& Operating } \\ \text { Contractor }\end{array} \\ \text { DOE } & \text { U.S. Department of Energy } \\ \text { DOT } & \text { U.S. Department of Transportation } \\ \text { DTN } & \text { Data Tracking Number } \\ \text { ft } & \text { Feet } \\ \text { m } & \text { Meter } \\ \text { ms } & \text { Millisecond } \\ \text { OCRWM } & \text { Office of Civilian Radioactive Waste Management } \\ \text { PVC } & \text { Poly Vinyl Chloride } \\ \text { psi } & \text { Pounds per Square Inch } \\ \text { s } & \text { Seconds } \\ \text { STN } & \text { Software Tracking Number } \\ \text { TBD } & \text { To be determined } \\ \text { TDV } & \text { To be Verified } \\ & \end{array}$




\section{OBJECTIVE AND SCOPE}

NSA Engineering, Inc., conducted seismic tomography surveys in Niche \#3 in the Exploratory Studies Facility (ESF), Yucca Mountain, Nevada, and Alcove \#8 in the Enhanced Characterization of the Repository Block (ECRB) cross drift as part of the Infiltration Experiment being conducted in Niche \#3. NSA Engineering is a direct support contractor to the Yucca Mountain Project. This report documents the work performed from August 14 through 30,2000 , prior to the beginning of the infiltration experiment.

The objective of the seismic tomography survey was to investigate the flow path of water between access drifts and more specifically to (Kramer 2000):

1. Conduct a baseline seismic tomography survey prior to the infiltration experiment;

2. Produce 2-D and 3-D tomographic images of the rock volume between Alcove \#8 and Niche \#3;

3. Correlate tomography results with published structural and lithological features, and with other geophysical data such as ground penetrating radar (GPR);

4. Results of this survey will form a baseline with which to compare subsequent changes to the rock mass. These changes may be as a result of the water infiltration tests that could be conducted in Alcove \#8 in 2001.

The scope of this reported work is to use the velocity tomograms to: (a) assess the structures and lithologic features within the surveyed area and/or volume between the two access drifts; and (b) provide information on the structural state of the rock mass as inferred by the velocity signatures of the rock prior to the beginning of the infiltration experiment.

\section{QUALITY ASSURANCE}

This report was prepared under Administrative Procedure AP-3.11Q Technical Reports in accordance with an approved development plan (CRWMS M\&O 1999a). A Quality Administrative Procedure AP-2.21Q Quality Determinations and Planning for Scientific, Engineering, and Regulatory Compliance Activities Activity Evaluation (CRWMS M\&O 1999b) was completed for this report, and the report was found to be quality affecting. The Quality Assurance Requirements and Description (DOE 2000) is applicable to this report.

All software and data were used on one computer. Access to the computer was controlled with password protection and access to the program was further controlled with a different password. A disk with a copy of the data will be included as Appendix A. Data will remain on the computer until verification of the receipt of the information in the Technical Data Management System (at which time it could safely be discarded). Data was transferred via compact disk when moved between computers or when placed in the Technical Data Management System. These steps meet the intent of AP-SI.1Q Control of the Electronic Management of Data. 


\subsection{COMPUTER SOFTWARE}

RockVision3 $\mathrm{D}^{\mathrm{TM}}$ software code, developed by NSA Engineering, was used for this application. The RockVision3D ${ }^{\mathrm{TM}}$ Version 91599 (STN: 10124-91599-00) was utilized to process the recorded seismic data (inputs) and produce tomographic images (outputs). The program is qualified for use on the Yucca Mountain Project under the AP-SI.1Q Software Management Procedure. It was obtained from Configuration Management, was appropriate for its intended use, and was used only within its range of validation. The software is loaded on Dell computer \#113095 located in cubical 1020B in Las Vegas. The software is a Windows based application.

\section{DESCRIPTION OF THE TEST CONFIGURATION (PLANNED)}

The test as planned consisted of seismic tomographic imaging of the rock volume between Niche \#3 in the ESF main loop drift and Alcove \#8 in the overlying ECRB cross drift. Figure 1 shows the proposed location of the test site within the ESF and ECRB, and Figures 2 and 3 show threedimensional representation of the test area including several boreholes that were drilled prior to the test. The six angled holes drilled downward from Alcove \#8 and the four holes drilled upward from Niche \#3 are to be used for data collection; the imaged area roughly corresponds to the rock volume enclosed by these 10 boreholes. The vertical distance between the two levels is approximately $23 \mathrm{~m}(75.5 \mathrm{ft})$. Figure 4 shows plan views of the hole collar locations within Alcove \#8 and Niche \#3.

In general, the planned survey involved generating a series of seismic signals from various source locations and measuring the travel time of the signals to an array of receivers placed on opposite sides of the rock volume from the source. The data are to be processed using NSA's RockVision3D ${ }^{\mathrm{TM}}$ software to develop a velocity model that specifies the seismic velocity at all points within the surveyed rock volume. The velocity model is to be evaluated by inspecting computer generated color images that represent velocity values on two-dimensional planar crosssections (tomograms) or as three-dimensional velocity contour surfaces. The images are to be used to identify boundaries between rock units having different seismic velocities and the location of zones characteristic of substantially lower seismic velocities, typically corresponding to fractured zones.

No specific industry standards are applicable to this report. Procedures used are documented in the NSA Engineering Tomographic Survey Scientific Notebook (Kramer 2000). Surveying information was obtained from the Technical Data Management System. This information has not been verified and quality products using this information would ordinarily be given a TBV or TBD number (To Be Verified, To Be Determined). However, in this report the surveying information is only used to roughly locate Alcove \#8 and Niche \#3 in relation to each other and not to design or engineer items connected to the two openings. Thus the TBV or TBD designation does not apply. 


\subsection{EQUIPMENT DESCRIPTION}

Figure 5 shows a schematic diagram of the data collection equipment and system connections. The primary seismic signal source is an Etrema magnetostrictive actuator inserted into a borehole and coupled to the rock with a hydraulic mechanism. A function generator provides a variable frequency signal that triggers data acquisition, controls seismic output from the source, and improves detection of seismic waves recorded by an array of receivers. The receivers are accelerometers that are mounted at regular intervals on a tube inserted into a borehole and forced against the rock surface with an inflatable bladder inside the tube. The signals are recorded by a high-resolution digital seismograph and saved as data files, which are subsequently processed using the RockVision3 ${ }^{\mathrm{TM}}$ software. The system was evaluated, and appropriate components were calibrated by the Standard and Calibration Laboratory of Bechtel Nevada Corporation. Serial numbers of equipment are listed in the NSA Engineering Tomographic Survey Scientific Notebook (Kramer 2000). Details of selected equipment are described below:

\section{Etrema seismic source}

The Etrema magnetostrictive actuator generates seismic shear ( $\mathrm{S}$-waves) and compressional (Pwaves) using the amplified output of a Hewlett-Packard function generator that provides a continuous sequence of a custom, swept-frequency signal. The actuator is coupled to the rock through a mechanism that is clamped to the borehole walls using hydraulic pressure of 2,000 $\mathrm{kPa}$ (300 psi). The assembly is inserted to the desired depth in the borehole and oriented using indexed, sectional lengths of PVC tubing. Figure 6 presents a schematic diagram of the source assembly.

\section{Accelerometer receivers}

The receiver probe consists of fifteen Endevco accelerometers (models 751-500 and 752-500) mounted on sectional lengths of PVC tubing that is inserted into the borehole to the required depth. The accelerometers are forced against the borehole wall using air pressure of $105 \mathrm{kPa}(15$ psi) to inflate a line hose extending through the tube assembly. The accelerometers are spaced 1 $\mathrm{m}(3.28 \mathrm{ft})$ apart, and the tubing sections are indexed to ensure that the receivers are aligned and oriented properly in the borehole. The output from the receivers is processed by an Endevco signal conditioner to provide an amplified input to the seismograph.

\section{Seismograph}

A Geometrics 24-channel high-resolution digital seismograph will be used to record and save the signal data from the receivers. The data are to be sampled at a rate of 16,000 samples per second. The first channel records the waveform supplied to the Etrema source, and channels 2 through 16 record the receiver data. The signal received from the accelerometers is correlated with the input signal to the seismic source and stored in the seismograph. Correlation of the signals reduces the amount of data stored. Correlation also improves the signal-to-noise in the data and allows the seismic records to be interpreted for seismic arrival times. The data files are saved in industry-standard SEG-2 format and are easily transferred to a PC-based computer for subsequent processing (Figure 5). 


\section{Other equipment}

The system is powered by AC power, provided by the ECRB site via an isolation transformer.

\subsection{SURVEY PROCEDURES}

The planned survey procedure involved activating the Etrema source at one-meter (3.28-ft) intervals in each of the six boreholes drilled from Alcove \#8 and recording signals at one-meter $(3.28-\mathrm{ft})$ intervals in each of the other nine holes. The receivers-inflataphone probe will be inserted in each hole in sequence and inflated to force the accelerometers against the rock surface. The Etrema source will be inserted to a given depth and activated, triggering the seismograph and recording one set of signals. The source will then be moved to the next depth until all locations in the source borehole had been recorded, after which the source will be moved to another borehole, and the sequence repeated. After data have been collected from all source holes, the probe will be removed and installed in the next borehole, and the entire sequence of source locations will be repeated. Thus, for each receiver location, the source will be activated numerous times at 1-m intervals within each of the other boreholes.

\section{DESCRIPTION OF THE TEST CONFIGURATION (AS-BUILT)}

Slight changes to the planned test configuration were required because of the geologic conditions and borehole availability encountered; however, attainment of the project objectives was unaffected. The following sections describe the required changes.

\subsection{EQUIPMENT DESCRIPTION}

Small adjustments to the original design of the Etrema source installation tubes and clamping device were required to enhance field operations; however, the basic functions were unchanged. These adjustments included: replacement of the original cables with lighter ones, strengthening of the PVC pipe joints, and adding an expansion limiter (Kramer 2000). Figure 7 illustrates the actual installation of source and receivers.

During installation of the source and receivers, lithophysae and fracture-related rock damage were encountered in the borehole walls that prevented installation of the equipment at the planned depths. Borehole video records were reviewed to assess the general conditions of the boreholes. In addition, a borehole camera was used to inspect the borehole walls, and a qualitative assessment of the size and location of lithophysae was made. The source and receivers were moved slightly, as needed, to place the source clamping mechanism and the receivers against solid rock. The locations of sources and receivers (Figure 3) used for subsequent processing illustrates that, although the spacings are not uniform, the actual locations provide a well-distributed coverage of the test area.

\subsection{SURVEY PROCEDURES}

The source, receivers, and function generator are connected to the seismograph by cables to transmit both seismic and trigger signals. At the time of the survey, the only access hole 
between Alcove \#8 and Niche \#3 was occupied by another installation, which made it unavailable for routing additional cables. Therefore, the sources and receivers could only be installed in the same group of holes accessed from a given level. Thus, cross-hole (source-toreceiver) tests were conducted between each of the six holes drilled downward from Alcove \#8 and between each of the four holes drilled upward from Niche \#3. The planned cross-hole tests between the upper (Alcove \#8) and lower (Niche \#3) holes could not be conducted.

To partially compensate for the lack of cross-hole data between the upper and lower holes, a series of measurements were recorded using hammer blows on the floor and walls of Alcove \#8, with receivers placed in the lower group of holes above Niche \#3.

\subsection{INPUT DATA}

Survey information was obtained from Design Input Transmittal 00274.T (CRWMS M\&O 2000) including DTN's MO0002GSC00064.000, MO0003GSC00103.000, and

MO0006GSC00241.000. These data included the collar (x,y,z) coordinates, the hole bearing and inclination, and deviations in alignment along the length if each hole. These data, together with the depths for each source and receiver location, were sufficient to provide the three-dimensional $(\mathrm{x}, \mathrm{y}, \mathrm{z})$ coordinates required to process the signal data.

\subsection{DATA ANALYSIS}

The figures for this report were obtained from the seismic tomography surveys conducted in Alcove \#8 and Niche \#3 (DTN: MO0012EBSSTINA.011). These surveys were processed using the RockVision3 ${ }^{\mathrm{TM}}$ program. This program takes information obtained from a seismograph and converts it into three-dimensional images or tomograms.

\section{SUMMARY OF DATA FROM THE TEST}

The data from the test consist of data files in SEG-2 format recorded by the seismograph for each source activation (Etrema location or hammer blow for a given receiver configuration), and the coordinates of each source and receiver location referenced to the corresponding data file. These data are sufficient to reproduce the results described in this report or to conduct a similar analysis using different analysis procedures or software.

Test data are included in DTN: MO0012EBSSTINA.011 and are attached as Appendix A. Dates for calibration of the equipment are included as part of the Scientific Notebook (Kramer 2000). These data meet the requirements of AP-SV.1Q Control of the Electronic Management of Data by limiting and controlling the transfer of data as discussed in Section 2.

\section{DISCUSSION OF THE TEST RESULTS}

The following sections describe the steps followed and assumptions made in producing tomographic images from the field data and the interpretation of the results with respect to physical conditions at the site. 


\subsection{DATA PROCESSING}

Data processing was conducted in two general steps: (1) evaluation of signal quality, and (2) generation of velocity models and tomograms. Evaluation of signal quality is largely a mechanical exercise to filter signal noise, identify erroneous data, and measure arrival times. Additionally, the potential resolution of the tomographic image can be determined to assist in configuring the tomogram calculation parameters. Generation of the velocity models is sitespecific and involves a degree of interpretation for selecting appropriate initial models and evaluating results. The following sections provide details of the procedures used to produce tomographic images of the test area.

\subsubsection{Evaluation of Signal Quality}

The first processing step involves calculating and entering $(\mathrm{x}, \mathrm{y}, \mathrm{z})$ coordinates for all source and receiver locations. Coordinates can be transformed (translation and rotation) to a local coordinate system for convenience in interpretation; however, the standard coordinate system used by the ECRB was used to permit relating the results to the overall facility layout. Next, the waveform traces are read from the seismograph data files, filtered to remove noise and enhance signal signature, and travel times are picked for each source-receiver pair. The program then generates a table of "rays," listing the coordinates and arrival times for each source-receiver pair. A plot can be generated, as shown in Figure 3, to verify the locations of sources and receivers and to identify erroneous coordinate data.

The Etrema source installed in a borehole generates predominantly seismic S-waves, and the hammer blows at the rock surface generate both S- and P-waves. Figure 8 shows example receiver traces from the $\mathrm{S}$-waves generated by the Etrema for measurements between holes 6 and 2 in Alcove \#8 and between holes 3 and 1 in Niche \#3. Figure 9 shows example receiver traces for receivers in the Niche \#3 holes from signals generated by hammer blows in Alcove \#8 near hole 2. The figure shows the arrivals of both P- and S-waves. The left plot in Figure 9 shows the signals resulting from a vertical hammer blow on the invert of Alcove \#8, and the right plot shows the signals resulting from a horizontal hammer blow on the wall of Alcove \#8. In general, the records from vertical hammer blows on the floor of Alcove \#8 were dominated by P-waves. S-waves were better defined for horizontal hammer blows on the walls next to holes 1 through 4 and on the concrete collar plates at holes 5 and 6 . The dominant frequency of the measured waves ranged from 800 to $1,200 \mathrm{~Hz}$. The frequency was assessed as an inverse of the wave periods measured as shown in Figure 8.

Figure 10 shows arrival time versus distance plots for four selected source records (top) and for $\mathrm{S}$-wave velocity data (bottom). The plots show relatively stable $\mathrm{S}$ - and P-wave velocity values $\left(\mathrm{V}_{\mathrm{s}}, \mathrm{V}_{\mathrm{p}}\right)$ in the survey area as indicated by the linear trend of the data for individual records and the consistent grouping of velocities (slopes of trend lines). The cross-hole measurements between the upper Alcove \#8 holes resulted in S-wave velocities of 1,665 m/s $(5,463 \mathrm{ft} / \mathrm{s})$, and measurements between the lower Niche \#3 holes resulted in S-wave velocities of 2,000 m/s $(6,562 \mathrm{ft} / \mathrm{s})$. The average $\mathrm{S}$-wave velocity resulting from the hammer blows, corresponding to signal travel through both the upper and lower zones, was $1,800 \mathrm{~m} / \mathrm{s}(5,906 \mathrm{ft} / \mathrm{s})$. The average Pwave velocity resulting from the hammer blows was $3,000 \mathrm{~m} / \mathrm{s}(9,843 \mathrm{ft} / \mathrm{s})$. The velocity values 
were calculated as distance traveled by selected waves over an average travel time as shown in Figure 10.

To assist in evaluating the accuracy of these velocity results, two parameters were calculated from the velocity data: Poisson's ratio and S-wave wavelength. Poisson's ratio, for an elastic, isotropic material is calculated by the relationship (Jaeger and Cook 1979, p. 185).

$$
v=\frac{1}{2}\left[\frac{\left(V_{p} / V_{s}\right)^{2}-2}{\left(V_{p} / V_{s}\right)^{2}-1}\right]
$$

where: $\mathrm{v}=$ Poisson's ratio

$V_{p}=$ P-wave velocity

$V_{s}=\mathrm{S}$-wave velocity

Substituting $3,000 \mathrm{~m} / \mathrm{s}$ for $\mathrm{V}_{\mathrm{p}}$ and $1,800 \mathrm{~m} / \mathrm{s}$ for $\mathrm{V}_{\mathrm{s}}$ results in a value of 0.22 for Poisson's ratio. This value is reasonable for the volcanic tuff rock type present at the site. A data tracking number for Geomechanics listed a Poisson's ratio of 0.22 for TSw2 rock (DTN:

LL990202204241.036).

The dominant frequency, $f$, of the $\mathrm{S}$-waves is on the order $1,000 \mathrm{~Hz}$ as shown in Figure 8 (note that a $\mathrm{Td}$ of $1 \mathrm{~ms}=1,000 \mathrm{~Hz})$. The wavelength of the $\mathrm{S}$-waves, $V_{s} / f$, varies from $1.67 \mathrm{~m}(1,665$ $\mathrm{m} / \mathrm{s} \div 1,000 \mathrm{~Hz})$ to $2.00 \mathrm{~m}(2,000 \mathrm{~m} / \mathrm{s} \div 1,000 \mathrm{~Hz})[5.46 \mathrm{ft}(5,460 \mathrm{ft} / \mathrm{s} \div 1,000 \mathrm{~Hz})$ to $6.56 \mathrm{ft}$ $(6,560 \mathrm{ft} / \mathrm{s} \div 1,000 \mathrm{~Hz})]$. The grid size of $0.8 \mathrm{~m}$ was used to generate both the velocity model and the final velocity tomographic image of the surveyed rock mass. The size of the grid defines resolution of the velocity tomograms. For wavelengths ranging from 1.6 to 2 meters, the size of the grid, and therefore the resolution of the tomograms was roughly half the wavelength.

\subsubsection{Generation of Velocity Models and Tomograms}

Once the ray path data were inputted, a tomographic inversion was constructed using a uniform (unknown) initial velocity model and straight ray paths to provide a preliminary velocity model of the test area. Figure 11 shows three-dimensional surface contours of representative S-wave velocities for two relatively uniform velocity zones identified in the preliminary velocity model. The figure illustrates an upper zone having a velocity of 1,695 m/s $(5,561 \mathrm{ft} / \mathrm{s}) \mathrm{immediately}$ below Alcove \#8 and a lower zone above Niche \#3 having a velocity of 1,900 m/s (6,234 ft/s). The open area between the upper and lower zones represents the approximate dipping plain of a transition zone between the upper and lower zones.

To find the zone boundary, color tomograms of velocities were generated for a series of twodimensional planar slices passing through the preliminary velocity model in the area surrounding the transition zone. The slices were generated at various orientations (strike azimuths of $90^{\circ}$, $210^{\circ}$ and $\left.330^{\circ}\right)$, dip angles $\left(8^{\circ}\right.$ to $\left.16^{\circ}\right)$ and elevations $(1,083$ to $1,085 \mathrm{~m}(3,553$ to $3,560 \mathrm{ft})$ ). The tomograms were evaluated with respect to three conditions: (1) uniformity of the color (velocity) distribution, indicating that the slice was within the same velocity zone; (2) symmetry of the color distribution, indicating alignment of the plane with the orientation of the transition zone; and (3) rate-of-change of velocity at different elevations, to identify the elevation of the zone 
boundary. Figure 12 shows example tomograms from various locations and illustrates how the color patterns are used to identify the transition zone boundary. From this preliminary assessment, the boundary was approximated as a plane passing through an elevation of 1,084 $\mathrm{m}$ $(3,556 \mathrm{ft})$ referenced to the center of the test area, with a strike azimuth of $330^{\circ}$ and dip of $12^{\circ}$ (to the northeast).

The initial, uniform velocity model was modified to include two zones, with $S$-wave velocities of $1,665 \mathrm{~m} / \mathrm{s}(5,463 \mathrm{ft} / \mathrm{s})$ assigned to the zone above the boundary plane and 2,000 m/s $(6,562 \mathrm{ft} / \mathrm{s})$ assigned to the zone below the boundary. The velocity numbers used were derived from Figure 10. Figure 13 shows a three-dimensional representation of the modified initial velocity model using color-coded velocity distribution plots on various planes passing through the model volume. Also shown in the figure is a red line connecting the upper boundary of significantly damaged rock in the six holes drilled downward from Alcove \#8. This boundary correlates with the presumed boundary of the transition zone.

A second tomographic inversion was constructed using the modified initial velocity model and curved ray paths. Figure 14 shows the resultant ray paths for all cross-hole and hammer sources. The high ray path density and full coverage throughout the survey area indicates that the results are applicable to nearly the entire survey area. Lateral coverage of the area immediately above Niche \#3 is limited by the narrow spread of the holes; thus, images produced within this region may be incomplete. Likewise, results obtained for areas outside the borehole "envelope" are based on extrapolations and should not be considered valid.

\subsection{DATA ANALYSIS}

Figure 15 presents a plot of the final velocity model resulting from the second tomographic inversion. Figure 16 emphasizes the location of the transition zone using a different set of velocity surface contours and also shows the locations and relative sizes of lithophysae detected by the borehole video camera. The plots show relatively uniform upper and lower zones and an explicit transition zone having a strike azimuth of $330^{\circ}$ and dip of $14^{\circ}$. The first $10 \mathrm{~m}$ of rock below Alcove \#8 appears relatively uniform, with a velocity of approximately 1,660 m/s $(5,446$ $\mathrm{ft} / \mathrm{s})$. Local clusters of lower velocity $(1,540 \mathrm{~m} / \mathrm{s}(5,052 \mathrm{ft} / \mathrm{s}))$ appear to match zones along the boreholes where larger lithophysae were identified when viewing the borehole video. Other clusters having higher velocities $(1,780 \mathrm{~m} / \mathrm{s}(5,840 \mathrm{ft} / \mathrm{s}))$ appear to match those areas along the boreholes that were more solid, with smaller lithophysae.

Review of Figure 16 indicates the presence of three separate layers within the transition zone:

- An upper layer, having an S-wave velocity of 1,540 m/s (5,052 ft/s), that occurs between elevations 1,084 and 1,086 $\mathrm{m}(3,556$ and 3,563 ft), referenced to the center of the test area. This layer matches a zone identified in the majority of holes drilled downward from Alcove \#8 characterized by larger sized lithophysae.

- A middle layer, having a velocity between 1,780 and $1,880 \mathrm{~m} / \mathrm{s}(5,840$ and $6,168 \mathrm{ft} / \mathrm{s})$, and located between elevations 1,081 and 1,084 $\mathrm{m}(3,547$ and 3,556 ft). The middle layer correlates with a zone of rock damaged by intense, nearly vertical fracturing. 
- A lower layer that is less well defined has a velocity of $1,540 \mathrm{~m} / \mathrm{s}(5,052 \mathrm{ft} / \mathrm{s})$ and occurs between elevations 1,079 and $1,081 \mathrm{~m}(3,540$ and 3,547 ft). This zone appears to match a zone of severely damaged rock observed near the top of holes 1 and 2 drilled upward from Niche \#3. Visually, the rock type in the transition zone appears similar to that observed in the relatively uniform rock approximately $7 \mathrm{~m}(23 \mathrm{ft})$ immediately above Niche \#3 having a velocity of 1,900 to $2,000 \mathrm{~m} / \mathrm{s}(6,234$ to $6,562 \mathrm{ft} / \mathrm{s})$.

Figure 17 shows a comparison of a velocity tomogram on a slice oriented parallel to the dip of the transition zone with a diagram of the geotechnical section of the Topopah Spring Tuff (D.C. Buesch and R.W. Spengler, p 20). In general, the regions delineated by the tomogram correlate well with the structure shown on the geotechnical section. Furthermore, the strike and dip of the transition zone matches the foliation data shown in Figure 18 (J.P. Rousseau, et al., p 46).

To more fully characterize the structure of the rock mass within the test area, a series of 16 tomograms was prepared on parallel, vertical slices, spaced at 1-m (3-ft) intervals. Figure 19 is a key showing the locations of the slices relative to Alcove \#8 and Niche \#3. The tomograms for each slice are shown in Figures 20 to 35. These tomograms provide additional detail of the present rock mass structure and will form the basis for identifying structural and hydrogeological changes arising from the planned water infiltration test. Such changes may include the introduction of saturated and partially saturated zones, identification of water flow paths, and detection of preferential flow pathways, for example, through fracture zones.

\subsection{CONCLUSIONS AND RECOMMENDATIONS}

The results of the tomographic survey of the Topopah Spring Tuff formation between Alcove \#8 and Niche \#3 yielded the following conclusions:

- Three distinct velocity zones were identified in the test area that correlate with an independently identified geotechnical section of the Topopah Spring tuff formation. The upper lithophysal zone and middle non-lithophysal zone of the formation were identified within the test area and are separated by a slightly dipping transition zone.

- The upper lithophysal zone extends from the invert of Alcove \#8 downwards to an elevation of $1,086 \mathrm{~m}(3,563 \mathrm{ft})$. The zone is relatively uniform with an average $\mathrm{S}$-wave velocity of $1,665 \mathrm{~m} / \mathrm{s}(5,463 \mathrm{ft} / \mathrm{s})$. There are clusters of local zones having lower velocities $(1,540 \mathrm{~m} / \mathrm{s}$; $5,052 \mathrm{ft} / \mathrm{s})$ and higher velocities $(1,780 \mathrm{~m} / \mathrm{s}(5,840 \mathrm{ft} / \mathrm{s}))$ associated with an increase or decrease, respectively, of the number and size of lithophysae.

- The middle non-lithophysal zone extends from the top of Niche \#3 upwards to an elevation of $1,080 \mathrm{~m}(3,543 \mathrm{ft})$. This zone is more uniform and has an average $\mathrm{S}$-wave velocity of 1,900 to $2,000 \mathrm{~m} / \mathrm{s}(6,234$ to $6,562 \mathrm{ft} / \mathrm{s})$.

- The transition zone is $7 \mathrm{~m}(23 \mathrm{ft})$ thick and is oriented with a strike azimuth of $330^{\circ}$ and a dip of $14^{\circ}$ to the northeast. This orientation correlates with published information regarding the bedding foliation near the survey area. 
- The transition zone is associated with a concentration of nearly vertical fractures adjacent to the contacts with the adjoining intact units.

- The transition zone is composed of three nearly parallel approximately $2-\mathrm{m}-(6.6-\mathrm{ft}-)$ thick layers:

a) The upper layer has an average $\mathrm{S}$-wave velocity of $1,540 \mathrm{~m} / \mathrm{s}(5,052 \mathrm{~m} / \mathrm{s})$. The lower velocity in this layer may be attributed to an increased number and/or size of lithophysae or fracturing in the layer.

b) The middle layer has an average velocity of 1,780 to $1,880 \mathrm{~m} / \mathrm{s}(5,840$ to $6,168 \mathrm{ft} / \mathrm{s})$ and coincides with an intensely fractured rock zone.

c) The lower layer has a velocity of $1,540 \mathrm{~m} / \mathrm{s}(5,052 \mathrm{ft} / \mathrm{s})$ and appears associated with local occurrences of lithophysae combined with fractures in the rock structure.

- The lower velocities in the transition zone may correspond to higher permeability due to the fractured rock structure. For the same reason, the zone may also be associated with perched water conditions.

- Topographic surveying information was not completely qualified and thus this document may be affected by technical product input information that requires confirmation. Any changes to the document that may occur as a result of completing the confirmation activities will be reflected in subsequent revisions. The status of the technical product input information quality may be confirmed by review of the DIRS database.

The results of the survey indicate the effectiveness of seismic tomography technology using the RockView3D ${ }^{\mathrm{TM}}$ software for three-dimensional imaging of underground structural features. Because the technique is non-destructive, a nearly identical survey of the test area can be repeated and can be particularly effective for identifying differences arising from the planned water infiltration test such as areas of increased saturation and flow paths.

It is recommended that the tomography results be correlated with plots of both mapped and projected joint and fracture zones and other known geologic and lithologic features within the surveyed rock volume. This will provide a better understanding of the structural state of the rock mass during the infiltration experiment in determining the water flow path. It is also recommended that the data obtained from the GPR test conducted in the surveyed area should be processed using the RockVision3 $\mathrm{D}^{\mathrm{TM}}$ software. This may further enhance the quality of the rock mass characterization.

It is highly recommended that additional tomographic surveys be conducted during various stages of the planned infiltration experiment to provide a view of developing flow channels "chimney effects" in the rock interior and establish a basis for evaluating changes in the rock mass over time. 


\section{REFERENCES}

\subsection{DOCUMENTS CITED}

Buesch, D.C. and Spengler, R.W. 1998. "Character of the Middle Nonlithophysal Zone of the Topopah Spring Tuff at Yucca Mountain." High-Level Radioactive Waste Management, Proceedings of the Eighth International Conference, Las Vegas, Nevada, May 11-14, 1998. Pages 16-23. La Grange Park, Illinois: American Nuclear Society. TIC: 237082.

CRWMS M\&O (Civilian Radioactive Waste Management System Management and Operating Contractor) 1998. Controlled Design Assumptions Document. B00000000-01717-4600-00032 REV 05. Las Vegas, Nevada: CRWMS M\&O. ACC: MOL.19980804.0481.

CRWMS M\&O 1999a. Development Plan for Data Reporting in Support of the Engineered Barrier System Testing Program. Development Plan TDP-EBS-ND-000001 REV 00. Las Vegas, Nevada: CRWMS M\&O. ACC: MOL.19990802.0315.

CRWMS M\&O 1999b. Engineered Barrier Systems Performance Testing for SR and LA (12012383MT). Activity Evaluation, June 23, 1999. Las Vegas, Nevada: CRWMS M\&O. ACC: MOL.19990630.0473.

CRWMS M\&O 2000. Surveying Information for Alcove 8 and Niche 3. Input Transmittal 00274.T. Las Vegas, Nevada: CRWMS M\&O. ACC: MOL.20000802.0007.

DOE (U.S. Department of Energy) 2000. Quality Assurance Requirements and Description. DOE/RW-0333P, Rev. 10. Washington, D.C.: U.S. Department of Energy, Office of Civilian Radioactive Waste Management. ACC: MOL.20000427.0422.

Jaeger, J.C. and Cook, N.G.W. 1979. Fundamentals of Rock Mechanics. 3rd Edition. New York, New York: Chapman and Hall. TIC: 218325.

Kramer, N.E. 2000. NSA Engineering Tomographic Survey Scientific Notebook. SN-M\&ODES-001-V1. ACC: MOL.20010302.0127.

Rousseau, J.P.; Kwicklis, E.M.; and Gillies, D.C. eds. 1999. Hydrogeology of the Unsaturated Zone, North Ramp Area of the Exploratory Studies Facility, Yucca Mountain, Nevada. WaterResources Investigations Report 98-4050. Denver, Colorado: U.S. Geological Survey. ACC: MOL.19990419.0335. 


\subsection{CODES, STANDARDS, REGULATIONS, AND PROCEDURES}

AP-2.21Q, Rev. 1, ICN 0, BSCN 1. Quality Determinations and Planning for Scientific, Engineering, and Regulatory Compliance Activities. Washington, D.C.: DOE, OCRWM. ACC: MOL.20010212.0018.

AP-3.11Q, Rev. 2. Technical Reports. Washington, D.C.: DOE, OCRWM. ACC: MOL.20010405.0010.

AP-SI.1Q, Rev. 3. Software Management. Washington, D.C.:DOE, OCRWM. ACC: MOL.2000405.0012.

AP-SV.1Q, Rev. 0, ICN 2. Control of the Electronic Management of Information. Washington, D.C.:DOE, OCRWM. ACC: MOL.20000831.0065.

\subsection{SOURCE DATA}

LL990202204241.036. Geomechanics. Submittal date: 02/08/1999.

MO0002GSC00064.000. Exploratory Studies Facilities (ESF) Niche \#3 (Niche 3107) Borehole As-Built Information. Submittal date: 02/09/2000.

MO0003GSC00103.000. Exploratory Studies Facility (ESF) Niche 3 Profile Alignment. Submittal date: 03/03/2000.

MO0006GSC00241.000. Exploratory Studies Facility (ESF) Alcove 8, Profile Alignment. Submittal date: 06/30/2000.

MO0012EBSSTINA.011. Seismic Tomographic Images Between Niche \#3 and Alcove \#8. Submittal date: 12/13/2000. 


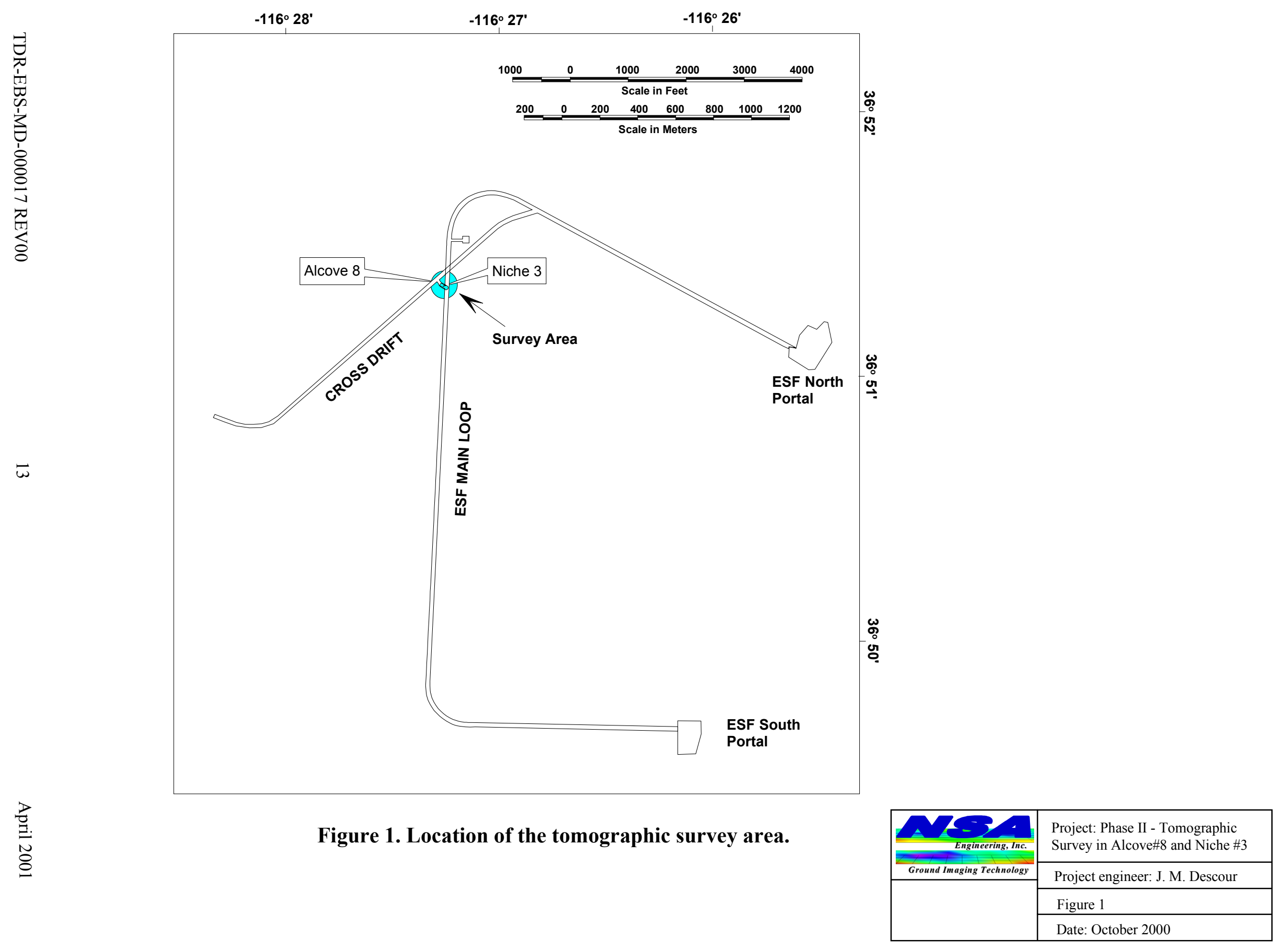




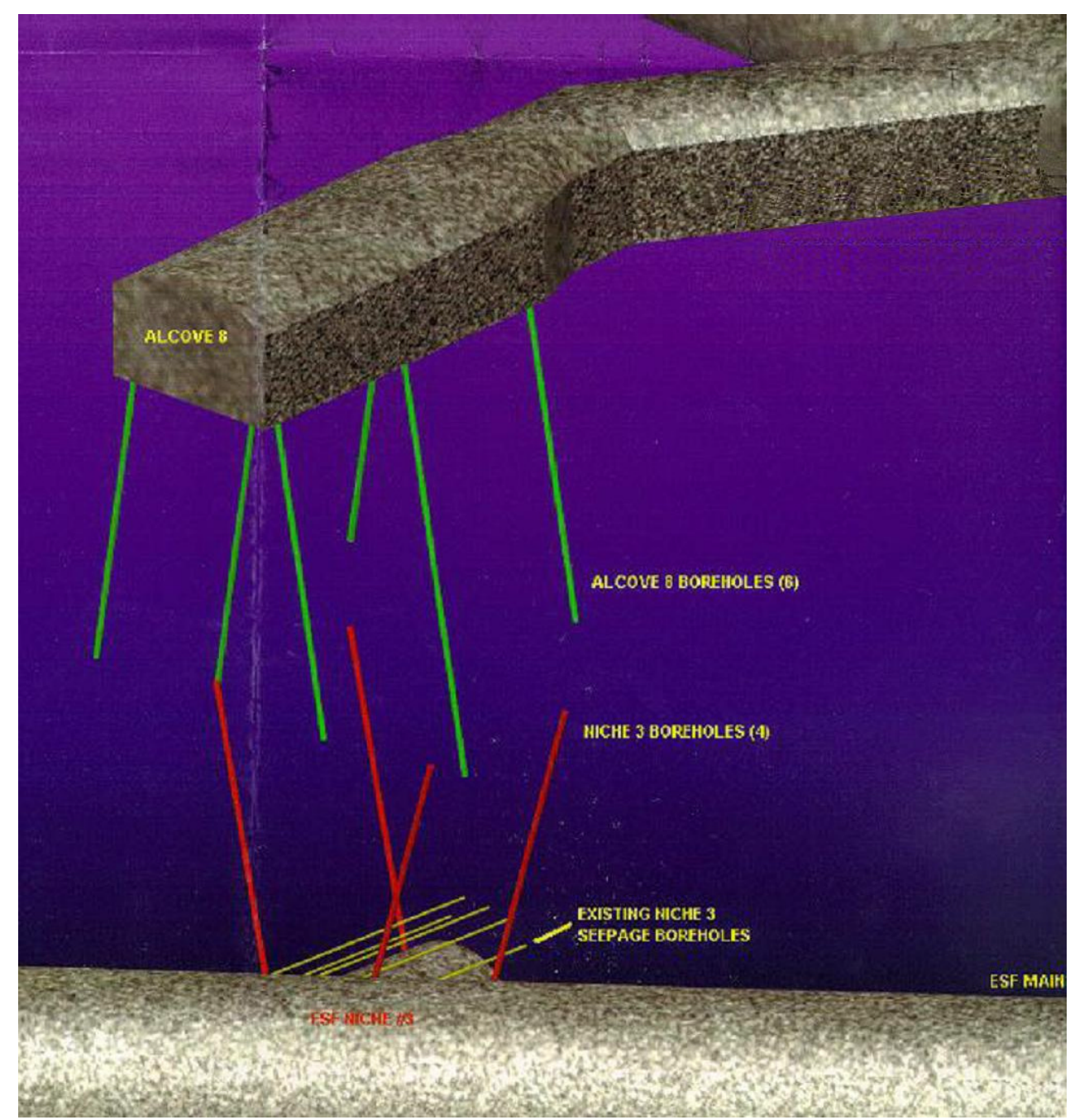

Do
E.
N
0

Figure 2. Three-dimensional projection of Alcove \#8 and Niche \#3 in the tomographic survey area.

\begin{tabular}{|c|l|}
\hline Eround Imaging Technology & Project: Phase II - Tomographic \\
\cline { 1 - 2 } & Survey in Alcove\#8 and Niche \#3 \\
\cline { 2 - 2 } & Figure 2 \\
\cline { 2 - 2 } & Date: October 2000 \\
\hline
\end{tabular}




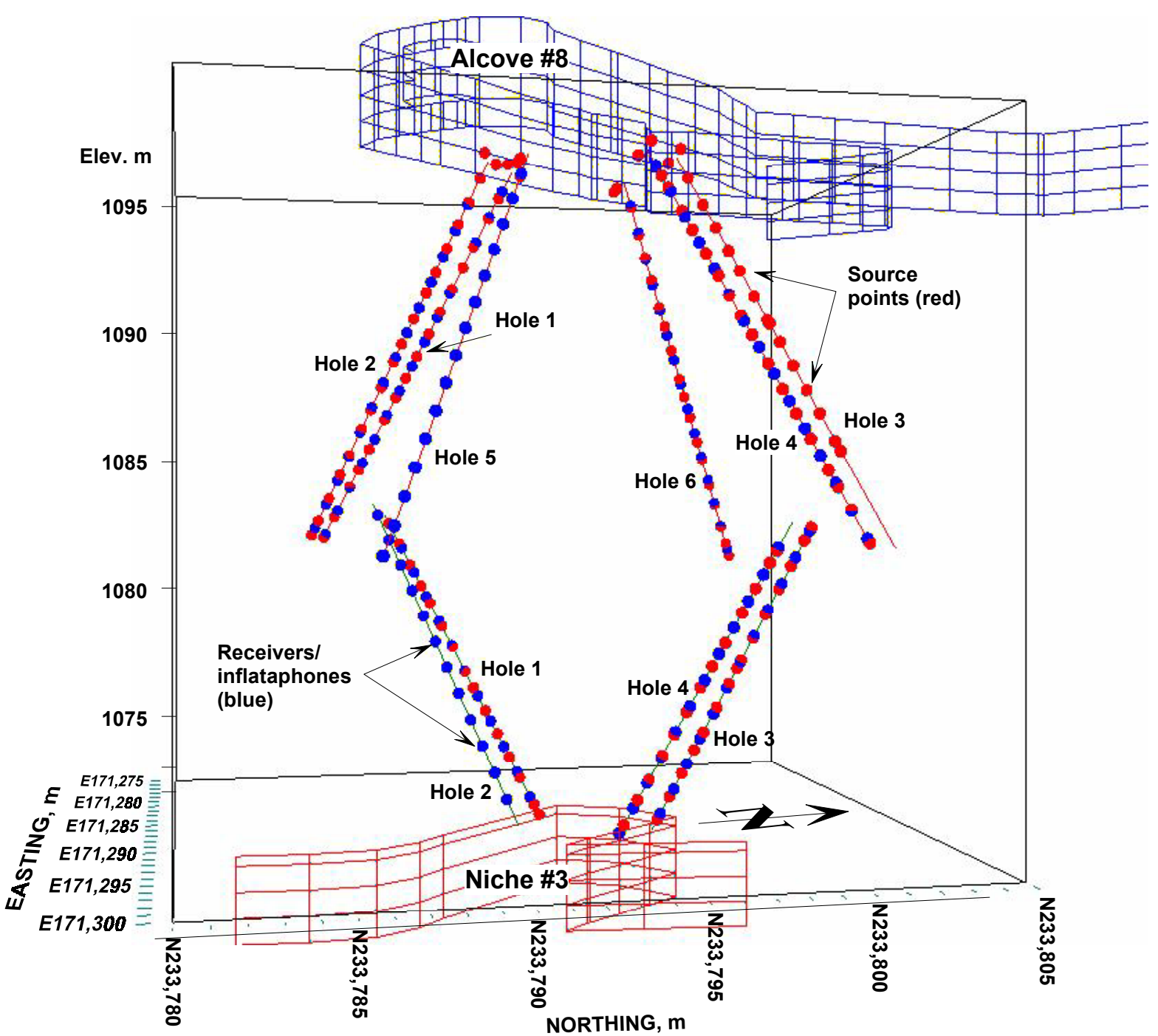

\begin{tabular}{|l|l|}
\hline Ground Imaging Technology & Project: Phase II - Tomographic \\
\cline { 2 - 2 } & Project engineer: J. M. Descour \\
\cline { 2 - 2 } & Figure 3 \\
\cline { 2 - 2 } & Date: October 2000 \\
\hline
\end{tabular}




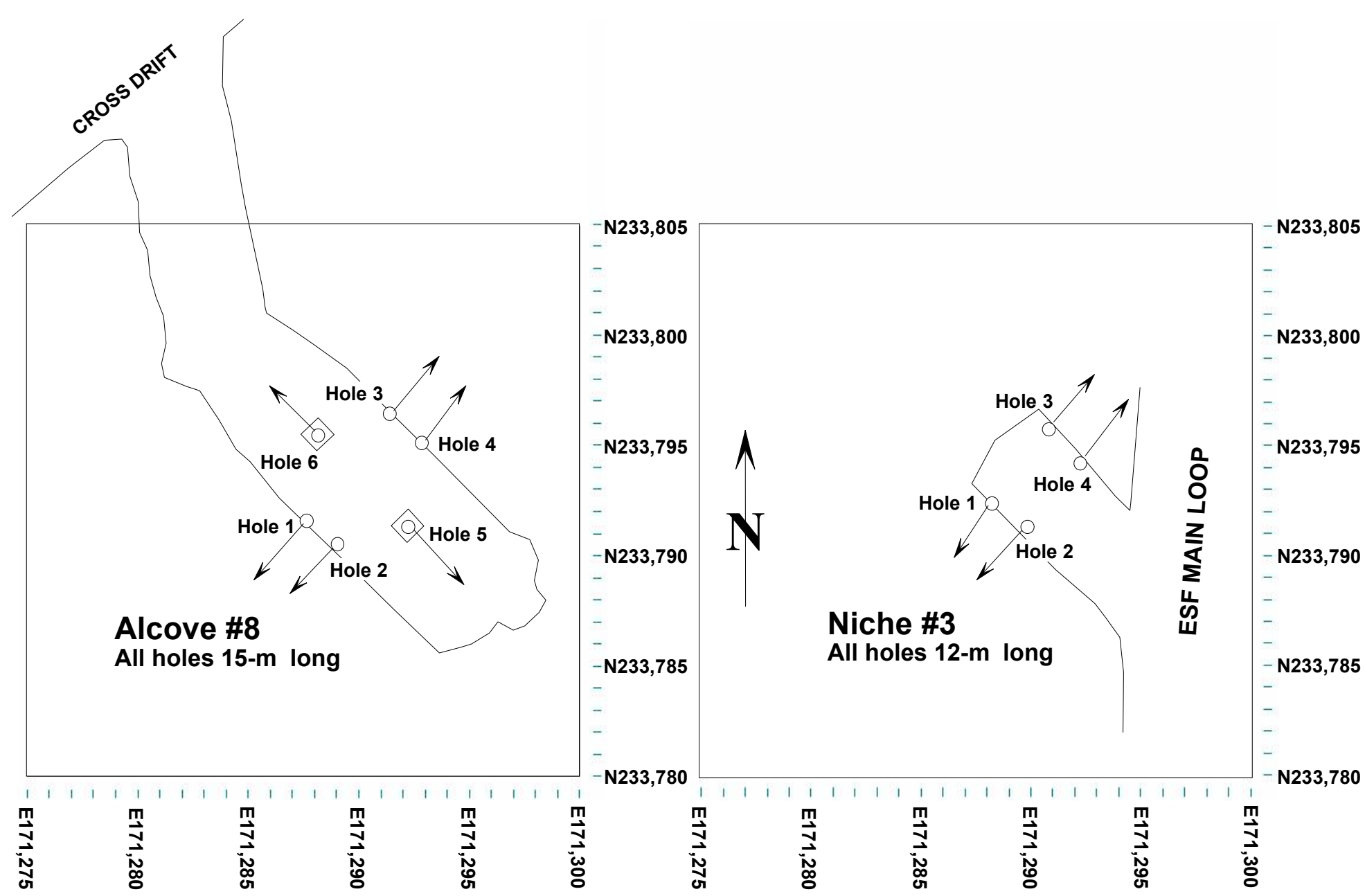

Figure 4. Plan view of Alcove \#8 and Niche \#3 with borehole locations and directions.

\begin{tabular}{|l|l|}
\hline Ground Imaging Technology & Project: Phase II - Tomographic \\
\cline { 1 - 2 } & Survey in Alcove\#8 and Niche \#3 \\
\cline { 2 - 2 } & Project engineer: J. M. Descour \\
\cline { 2 - 2 } & Figure 4 \\
\cline { 2 - 2 } & Date: October 2000 \\
\hline
\end{tabular}




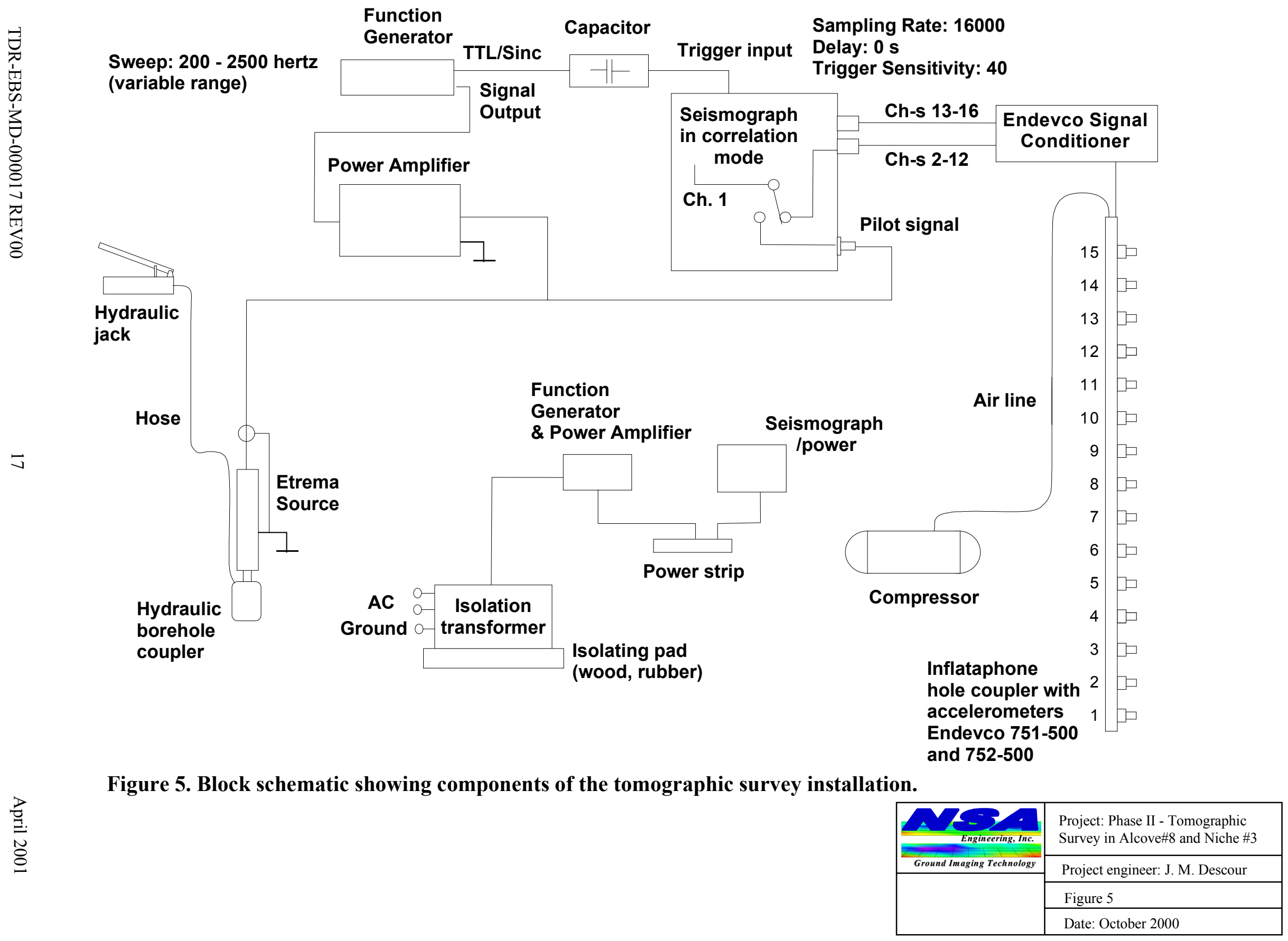




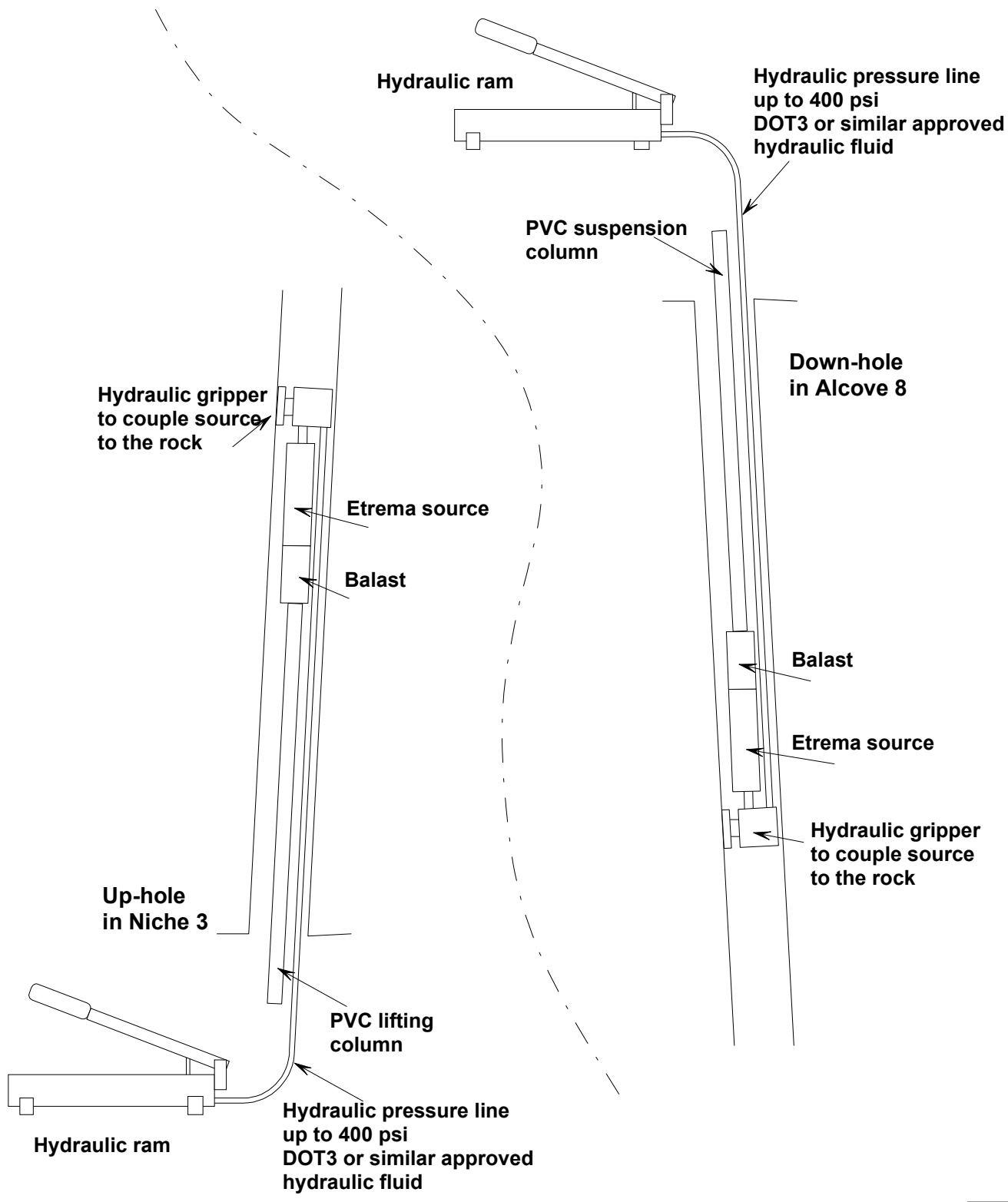
dry holes in Alcove \#8 and Niche \#3.

\begin{tabular}{|l|l|}
\hline Ground Imaging Technology & $\begin{array}{l}\text { Project: Phase II - Tomographic } \\
\text { Survey in Alcove\#8 and Niche \#3 }\end{array}$ \\
\cline { 1 - 2 } & Project engineer: J. M. Descour \\
\cline { 2 - 2 } & Figure 6 \\
\cline { 2 - 2 } & Date: October 2000 \\
\hline
\end{tabular}




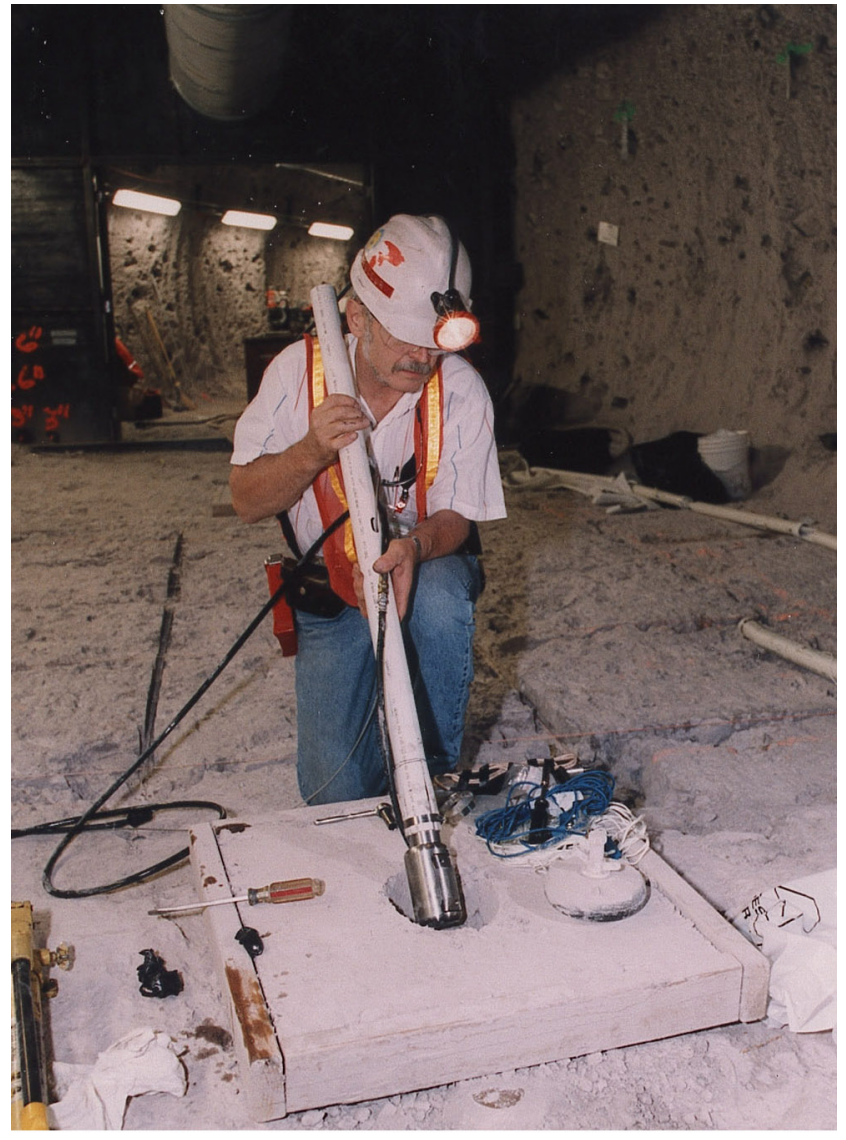

YM-20704 Acoustic Tomography Testing Activities In Alcove 8

\section{Seismic Source}

Figure 7. Installation of seismic source and accelerometers - inflataphone probe assembly.

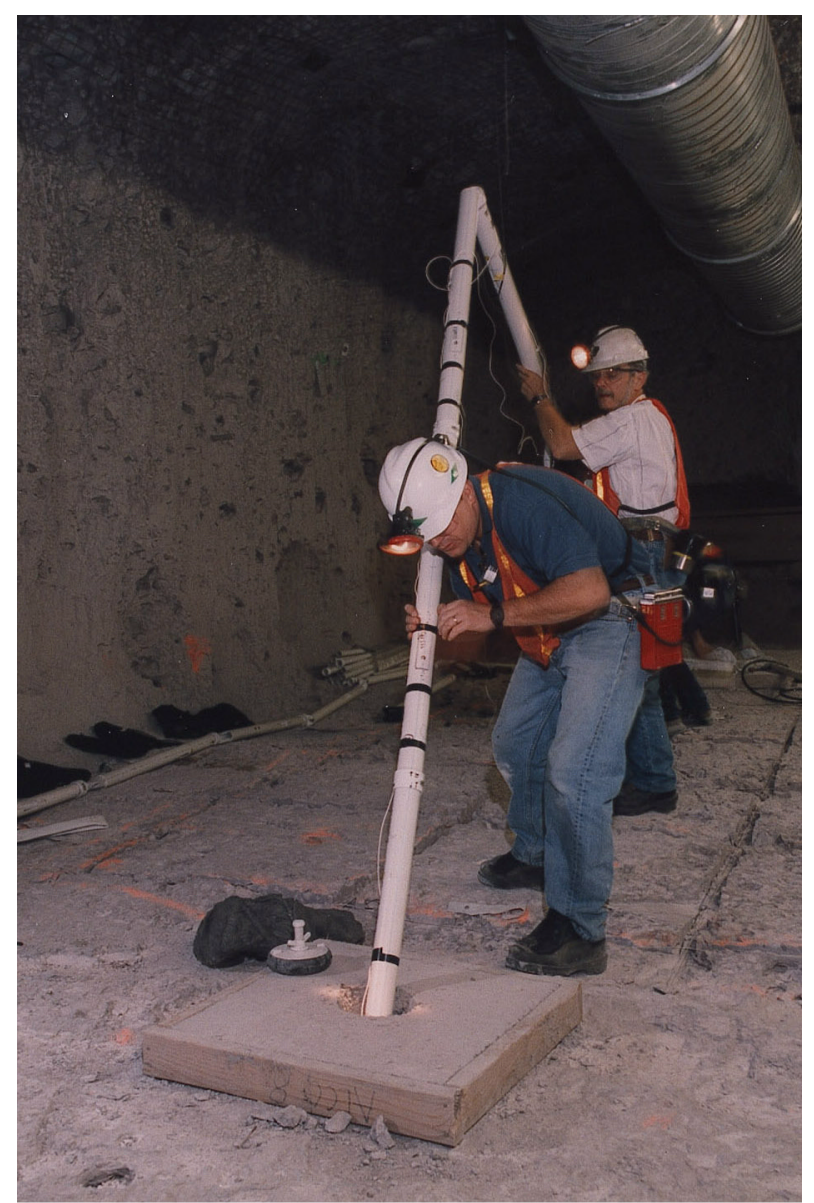

YM-20706 Acoustic Tomography Testing Activities In Alcove 8.

Accelerometers - Inflataphone Probe Assembly

\begin{tabular}{|l|l|}
\hline Ground Imaging Technology & $\begin{array}{l}\text { Project: Phase II - Tomographic } \\
\text { Survey in Alcove\#8 and Niche \#3 }\end{array}$ \\
\cline { 1 - 2 } & Project engineer: J. M. Descour \\
\cline { 2 - 2 } & Figure 7 \\
\cline { 2 - 2 } & Date: October 2000 \\
\hline
\end{tabular}




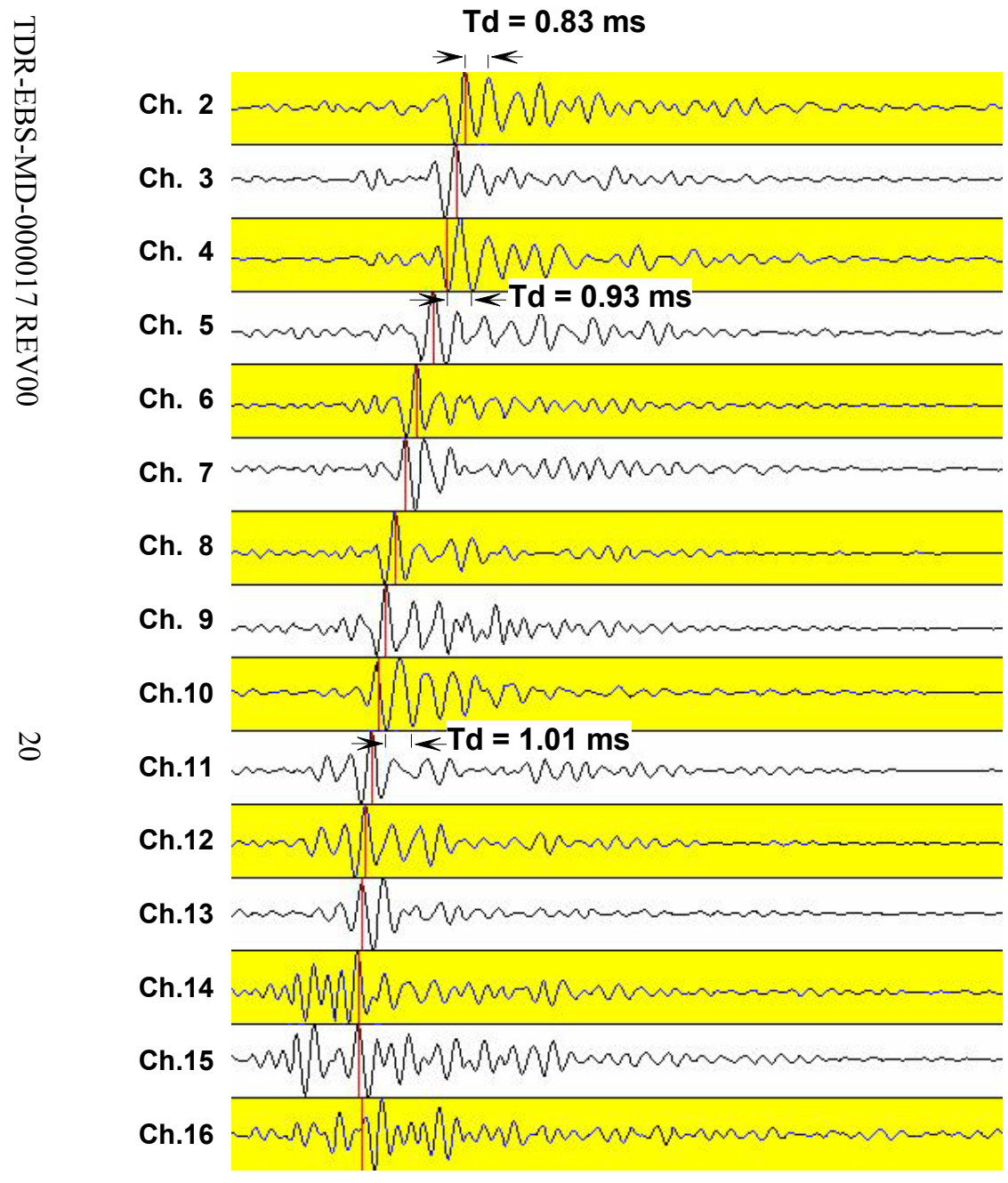

0

TIME, ms

Alcove \#8 between holes 6 and 8

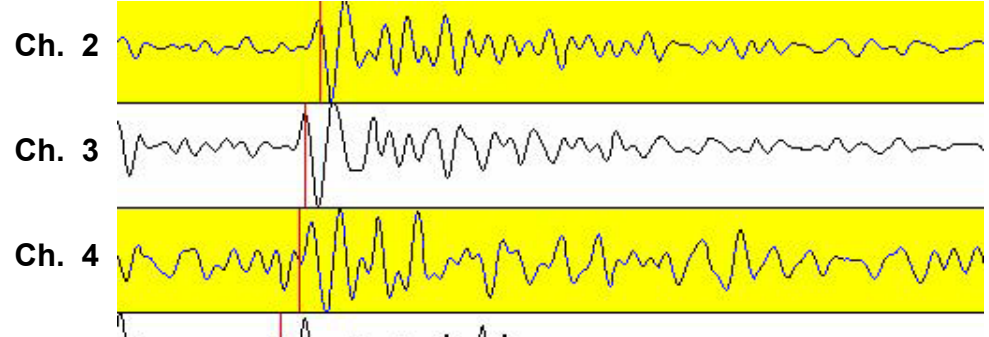

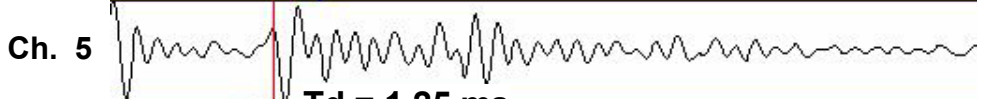

Ch. $6 \underbrace{}_{\rightarrow}$

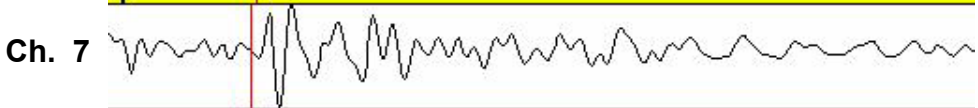

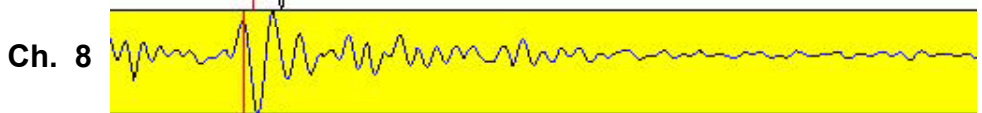

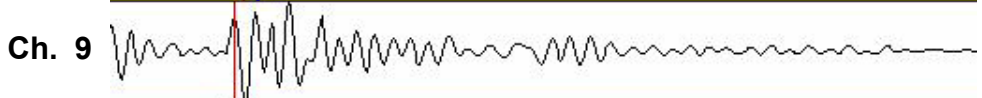

Ch.10 mand MWhNAm

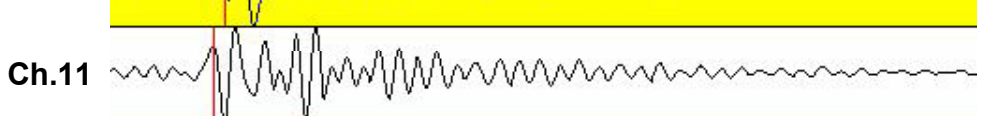

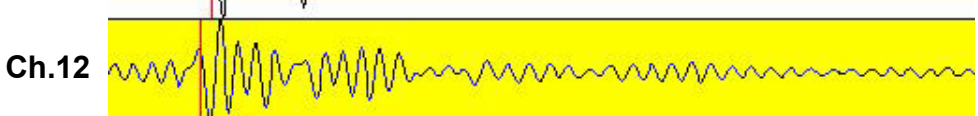

ch.13

$0 \quad \mathrm{Td}=1.01 \mathrm{~ms} \quad$ TIME, $\mathrm{ms}$

30

Niche \#3 between holes 3 and 1
Figure 8. S-wave records from Alcove \#8 and Niche \#3 using the Etrema source.

\begin{tabular}{|l|l|}
\hline Ground Imaging Technology & $\begin{array}{l}\text { Project: Phase II - Tomographic } \\
\text { Survey in Alcove\#8 and Niche \#3 }\end{array}$ \\
\cline { 1 - 2 } & Project engineer: J. M. Descour \\
\cline { 2 - 2 } & Figure 8 \\
\cline { 2 - 2 } & Date: October 2000 \\
\hline
\end{tabular}


Ch. $1 \mathrm{M} / \mathrm{N} \Omega$ Trigger signal

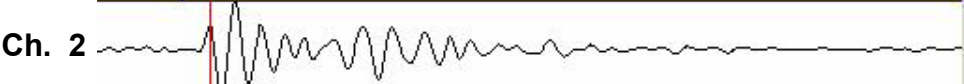

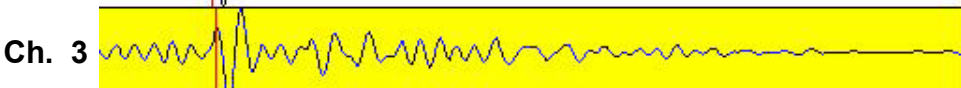

ch. 4 m NVNMWNNAN)

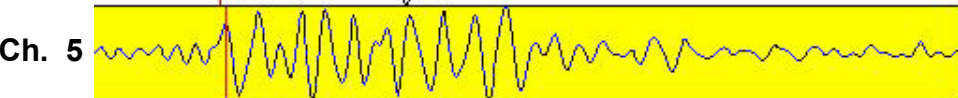

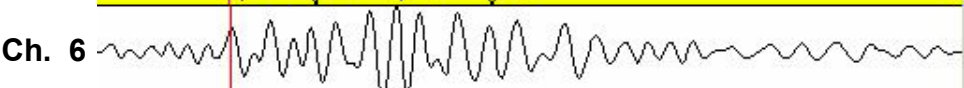

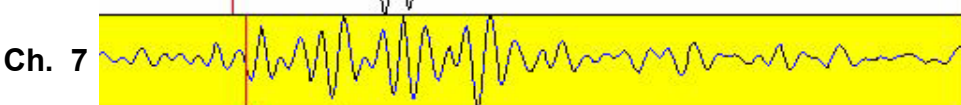

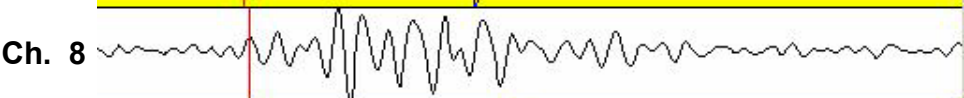

$\stackrel{N}{\simeq}$

ch. 9 minn

P-Waves

$\frac{8}{0}$

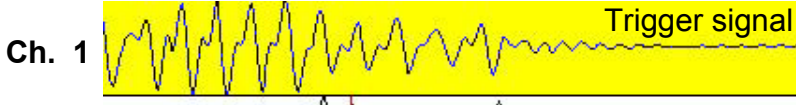

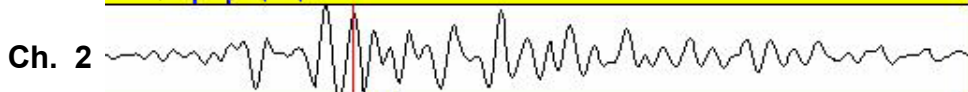

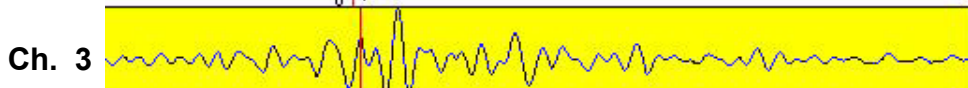

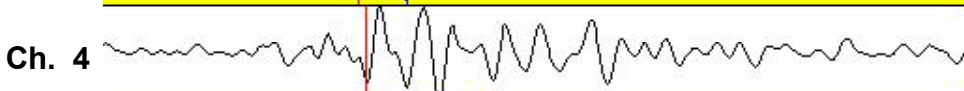

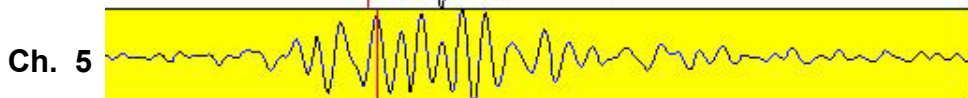

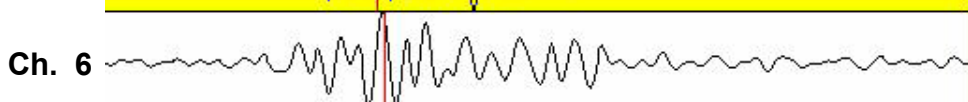

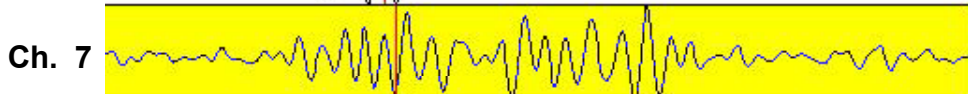

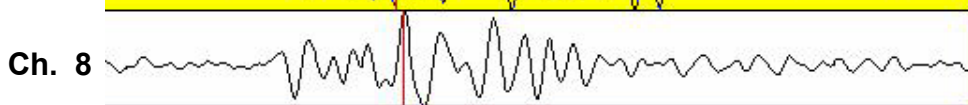

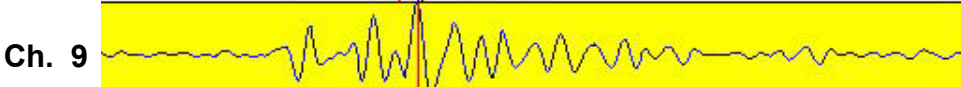

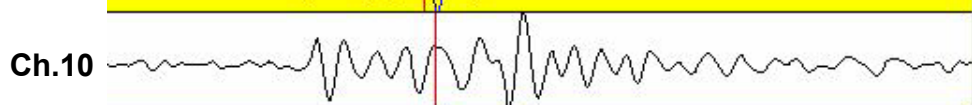

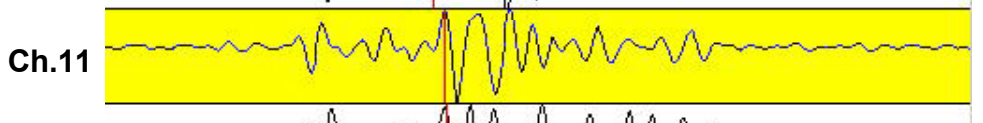

ch.12 年m

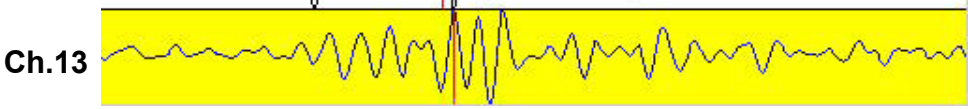

0

TIME, ms

S-Waves
30

\begin{tabular}{|l|l|}
\hline Ground Imaging Technology & $\begin{array}{l}\text { Project: Phase II - Tomographic } \\
\text { Survey in Alcove\#8 and Niche \#3 }\end{array}$ \\
\cline { 2 - 2 } & Project engineer: J. M. Descour \\
\cline { 2 - 2 } & Figure 9 \\
\cline { 2 - 2 } & Date: October 2000 \\
\hline
\end{tabular}

Figure 9. P-waves and S-waves recorded from Niche \#3 using hammer strikes in Alcove \#8. 

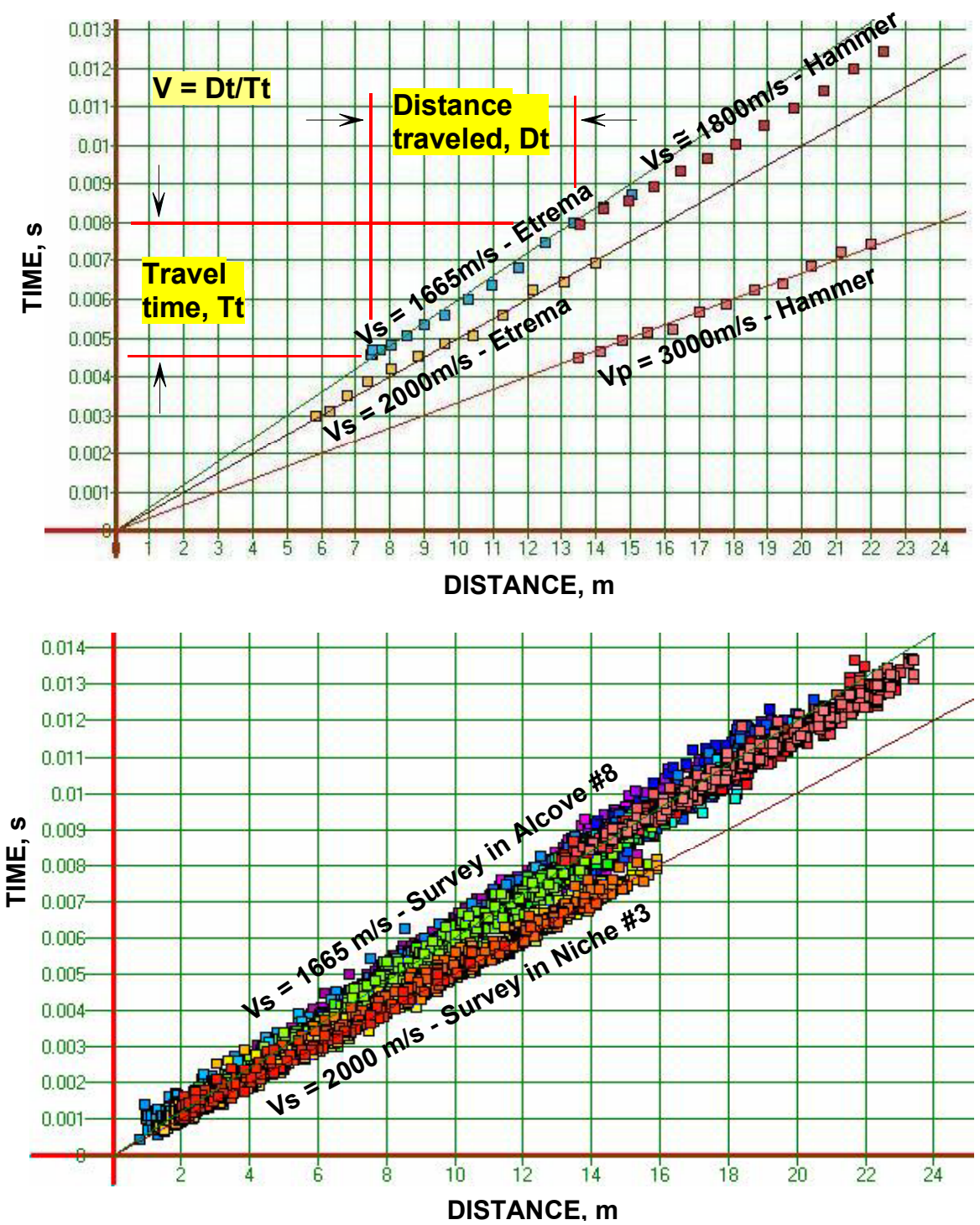

Selected Source Locations

S-Wave Velocity Data 


\section{Color code}

S-wave

velocity, $\mathrm{m} / \mathrm{s}$

2100

2000

1900

1800

$-$

N

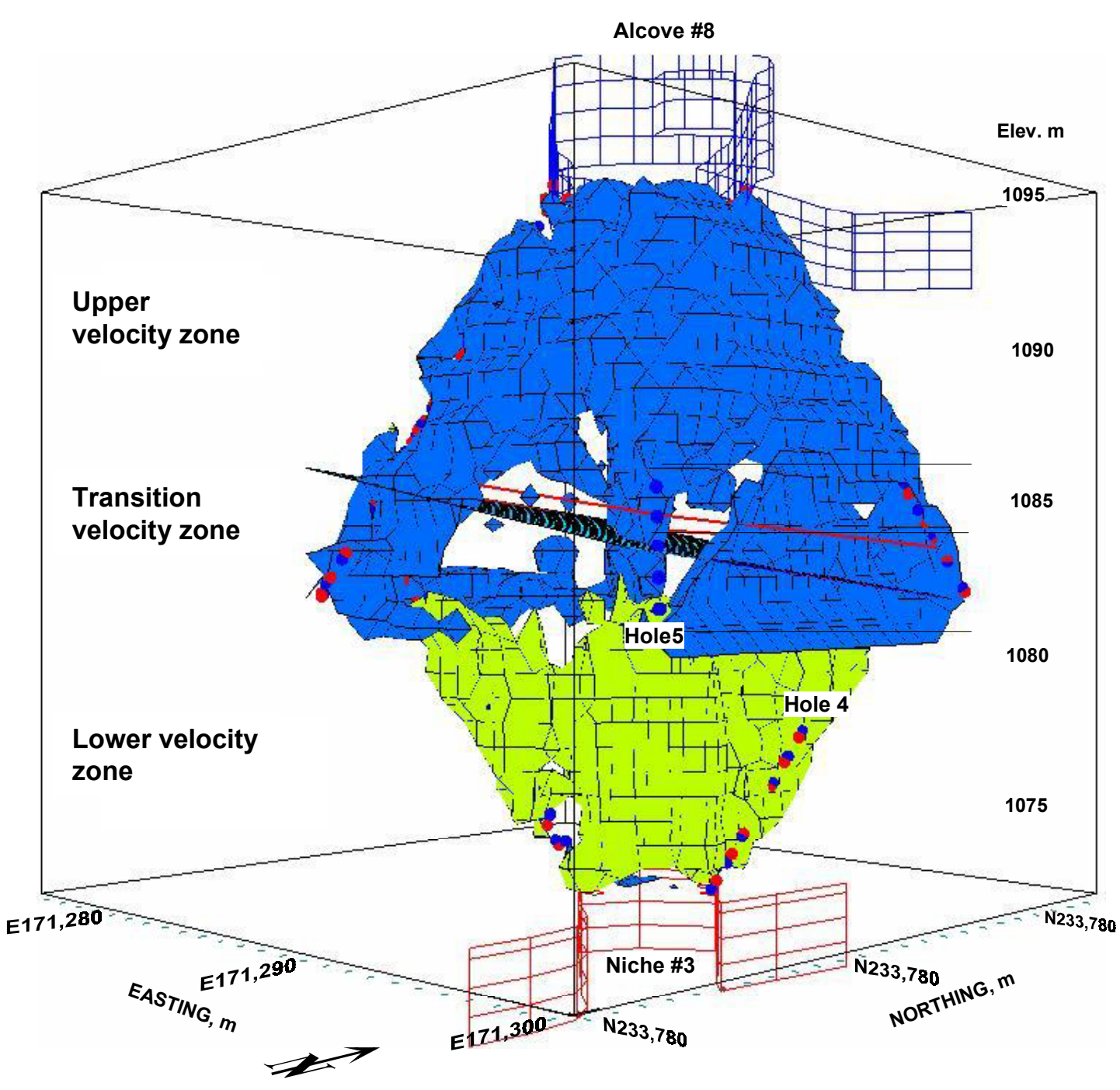

Figure 11. S-wave velocity contours generated without initial velocity model showing two relatively uniform rock zones above and below a transition zone.

\begin{tabular}{|c|l|}
\hline Eround Imaging Technology & $\begin{array}{l}\text { Project: Phase II - Tomographic } \\
\text { Survey in Alcove\#8 and Niche \#3 }\end{array}$ \\
\hline & Project engineer: J. M. Descour \\
\cline { 2 - 2 } & Figure 11 \\
\cline { 2 - 2 } & Date: October 2000 \\
\hline
\end{tabular}




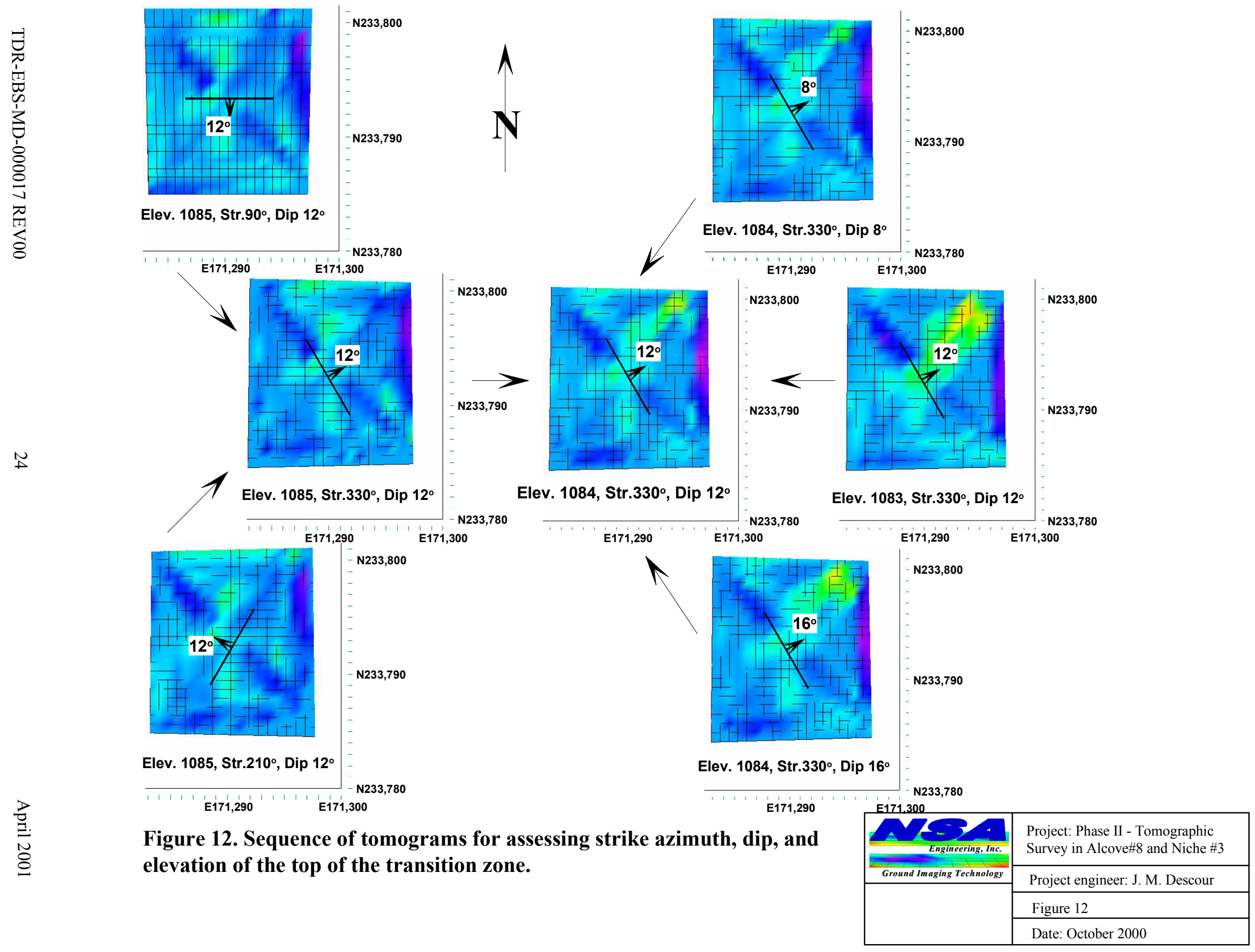




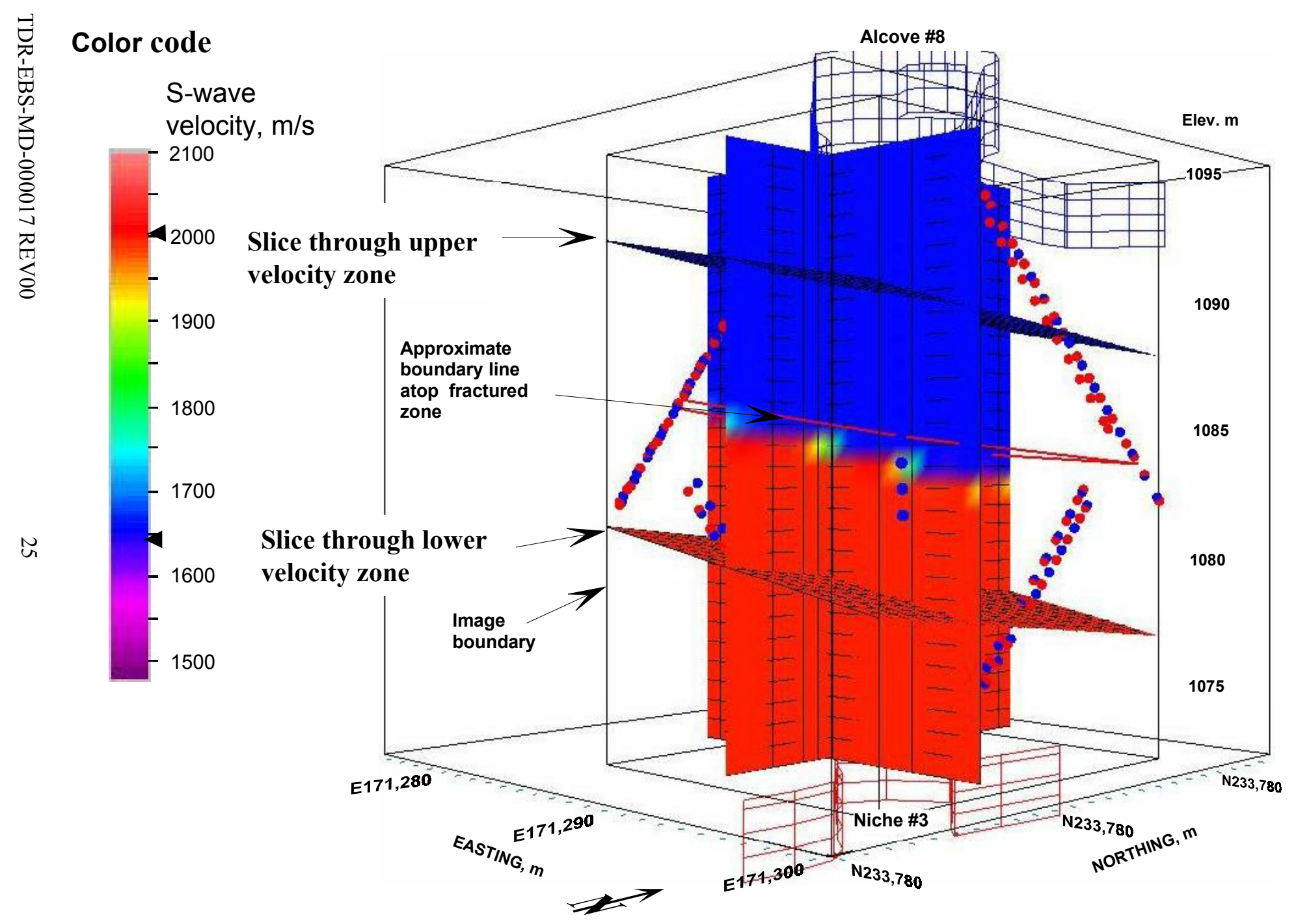

$\frac{8}{0}$
量
。

Figure 13. Three-dimensional representation of the initial S-wave velocity model.

\begin{tabular}{|l|l|}
\hline Ground Imaging Technology & Project: Phase II - Tomographic \\
& Survey in Alcove\#8 and Niche \#3 \\
\hline \multirow{4}{*}{} & Project engineer: J. M. Descour \\
\cline { 2 - 2 } & Figure 13 \\
\cline { 2 - 2 } & Date: October 2000 \\
\hline
\end{tabular}




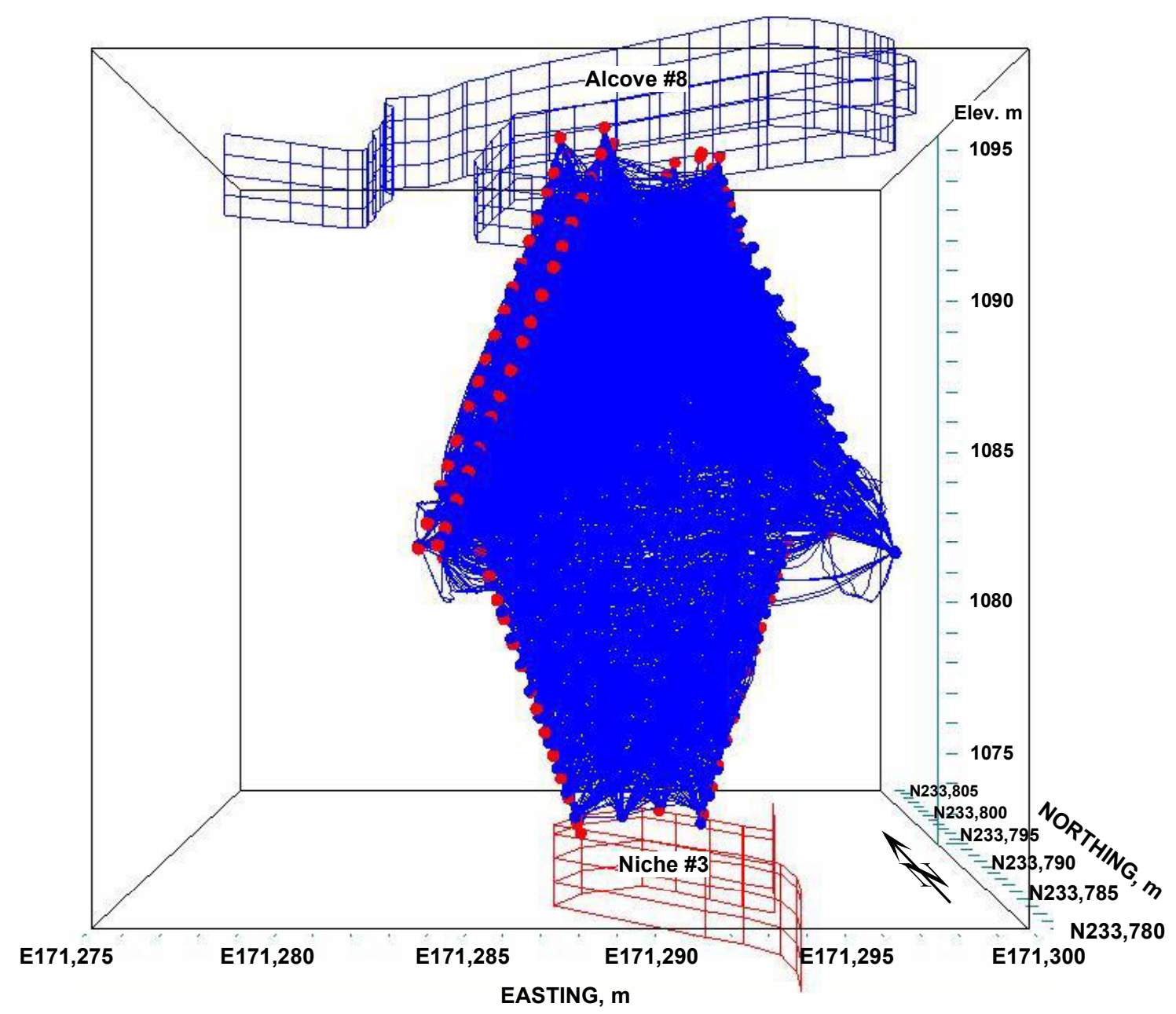

\begin{tabular}{|l|l|}
\hline Eround Imaging Technology & Project: Phase II - Tomographic \\
& Survey in Alcove\#8 and Niche \#3 \\
\cline { 2 - 2 } & Project engineer: J. M. Descour \\
\cline { 2 - 2 } & Figure 14 \\
\cline { 2 - 2 } & Date: October 2000 \\
\hline
\end{tabular}




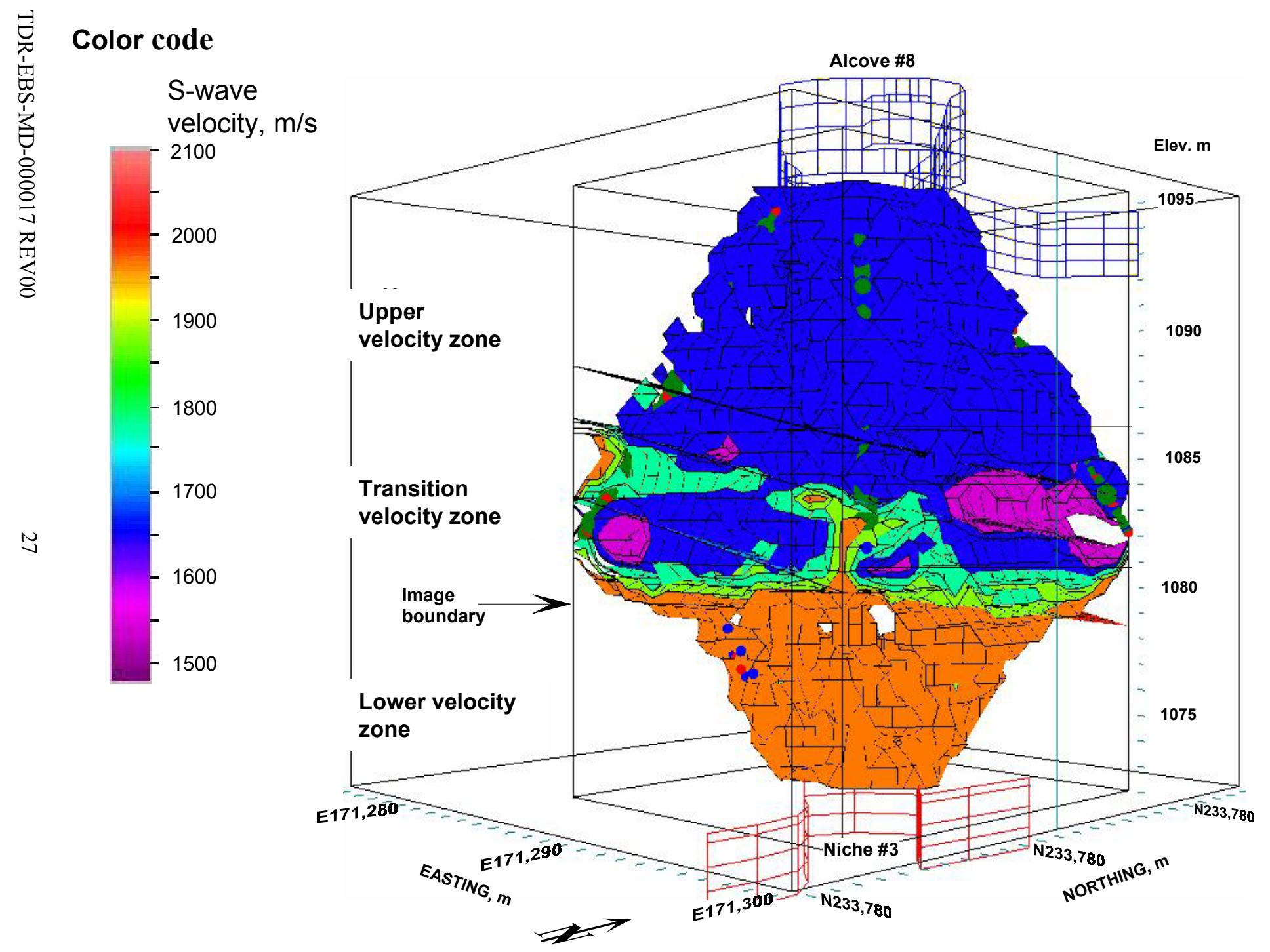

\begin{tabular}{|l|l|}
\hline Ground Imaging Technology & Project: Phase II - Tomographic \\
\cline { 1 - 2 } & Survey in Alcove\#8 and Niche \#3 \\
\cline { 2 - 2 } & Project engineer: J. M. Descour \\
\cline { 2 - 2 } & Figure 15 \\
\cline { 2 - 2 } & Date: October 2000 \\
\hline
\end{tabular}




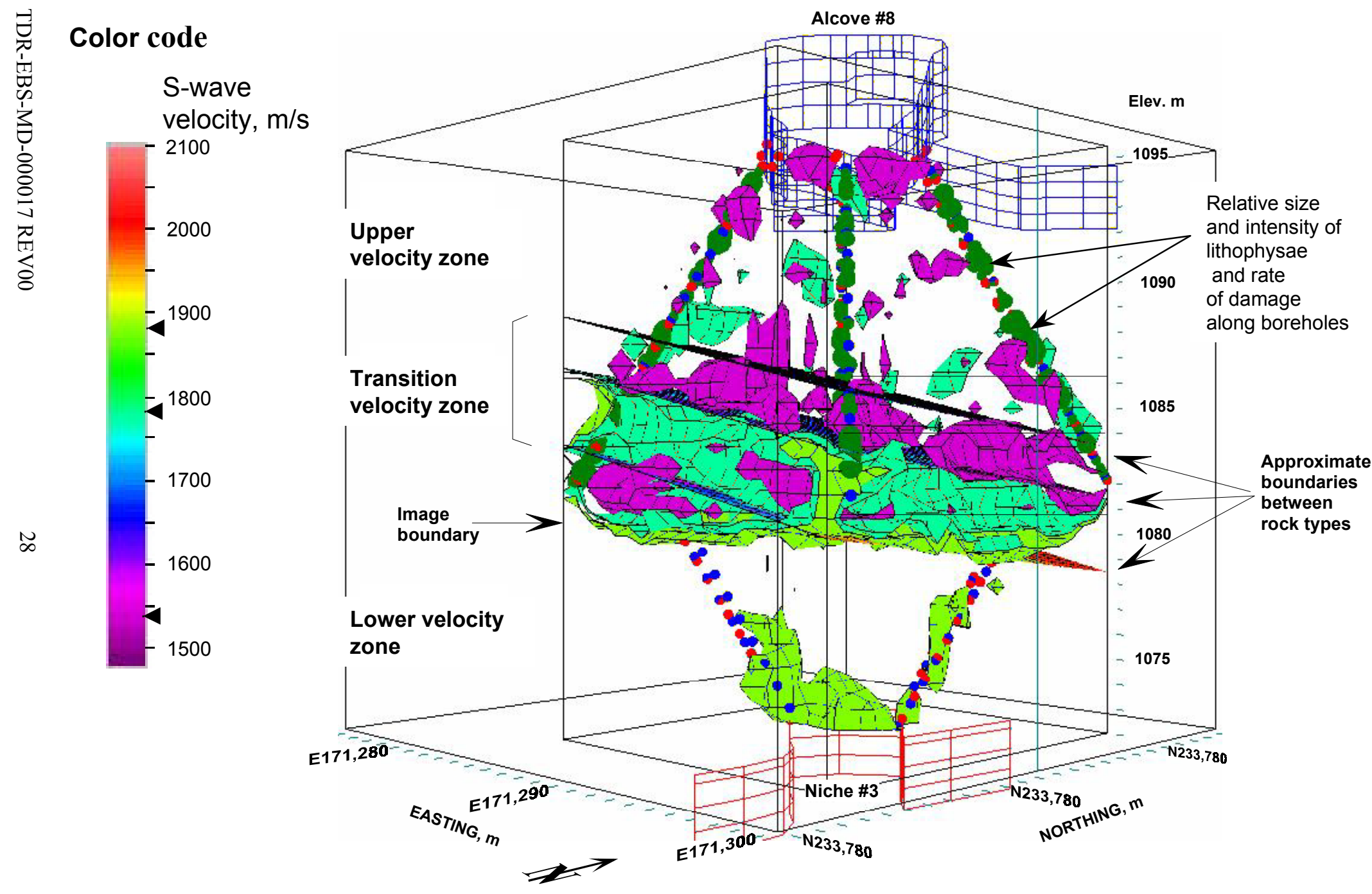

Figure 16. Refined S-wave velocity contours showing well-defined fractured transition zone. Green spheres represent qualitative size assessment of larger voids associated with lithophysae or fractured rock along each borehole.

\begin{tabular}{|l|l|}
\hline Ground Imaging Technology & $\begin{array}{l}\text { Project: Phase II - Tomographic } \\
\text { Survey in Alcove\#8 and Niche \#3 }\end{array}$ \\
\hline & Project engineer: J. M. Descour \\
\cline { 2 - 2 } & Figure 16 \\
\cline { 2 - 2 } & Date: October 2000 \\
\hline
\end{tabular}


NOTICE:

SPECIAL HANDLING INSTRUCTIONS

QA: N/A

Document Identifier: TDR-EBS-MD-000017

Seismic Tomography Technology for the Water Infiltration

Document Title: Experiment

Document Revision Designator: REV. 00

Document Date:

$04 / 2001$

This document requires special handling in accordance with AP-6.1Q.

$\checkmark$ Do NOT copy without permission.

$\checkmark$ Do NOT image or post online.

$\checkmark$ Place in a locked file cabinet or in a locked office when not attended. 
Illegibility does not impact the technical meaning or content of the record.

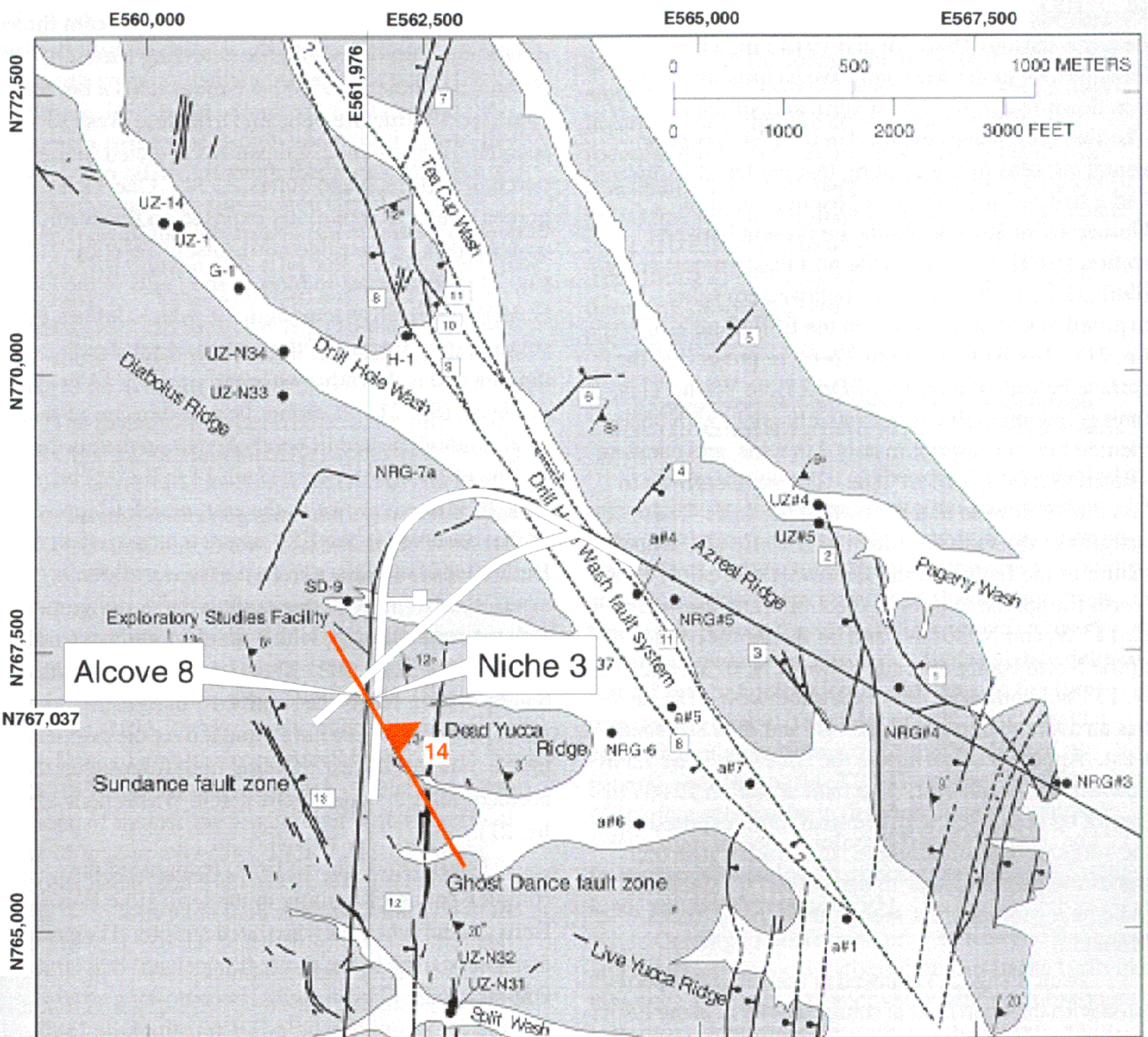

(after J. P. Rousseau et al., p 46)

Figure 18. Strike and dip of the transition zone determined by the tomographic survey in relation to the Sundance fault zone and rock foliation near the survey site.

\begin{tabular}{|l|l|}
\hline Ground Imaging Technology & $\begin{array}{l}\text { Project: Phase II - Tomographic } \\
\text { Survey in Alcove\#8 and Niche \#3 }\end{array}$ \\
\cline { 1 - 2 } & Project engineer: J. M. Descour \\
\cline { 2 - 3 } & Figure 18 \\
\cline { 2 - 3 } & Date: October 2000 \\
\hline
\end{tabular}




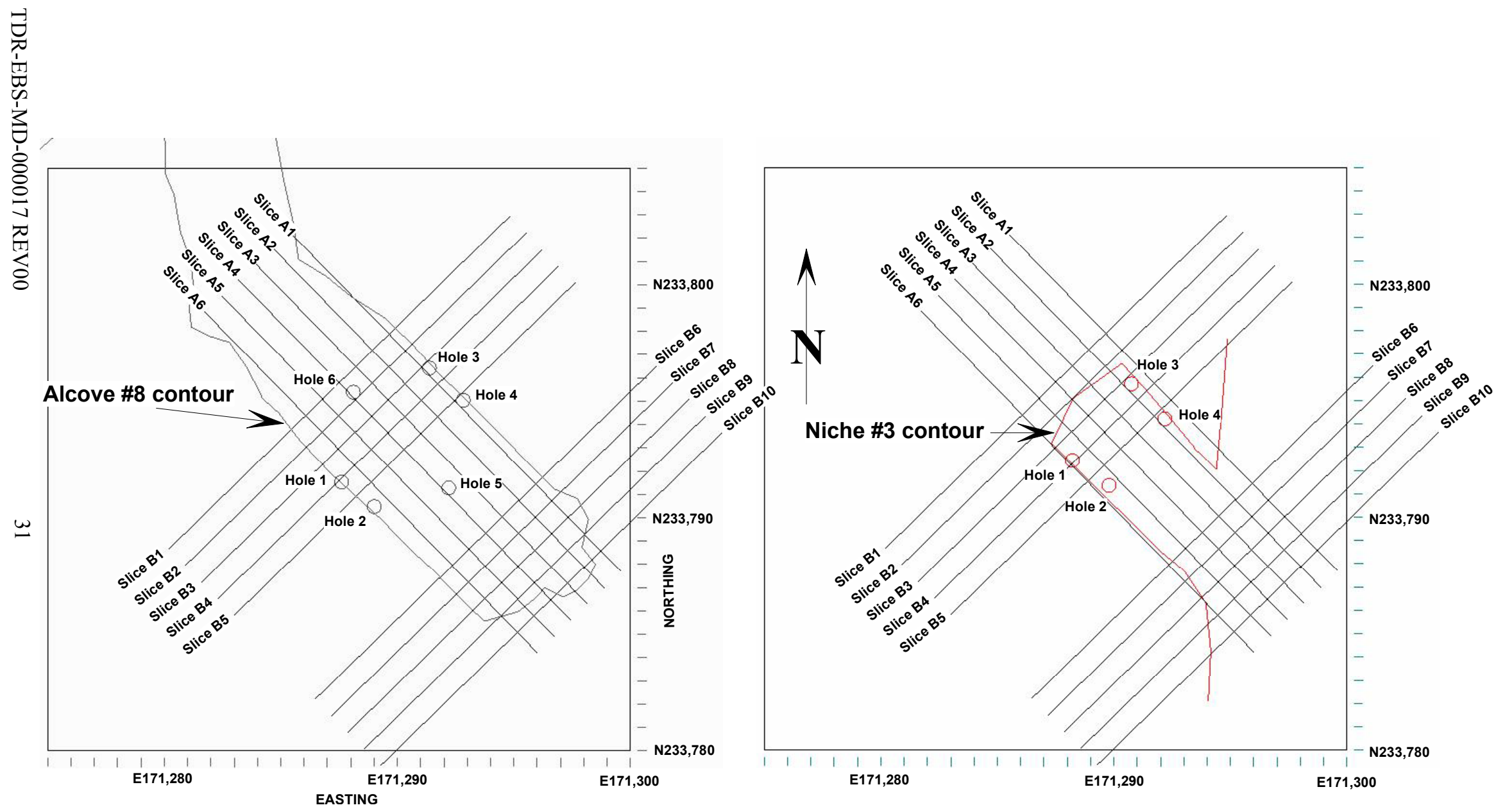

Figure 19. Plan view showing location of vertical slices spaced at $1 \mathrm{~m}$ apart.

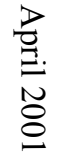

\begin{tabular}{|l|l|}
\hline Ground Imaging Technology & Project: Phase II - Tomographic \\
\cline { 1 - 2 } & Survey in Alcove\#8 and Niche \#3 \\
\cline { 1 - 2 } & Figure 19 19 \\
\cline { 2 - 2 } & Date: October 2000 \\
\hline
\end{tabular}




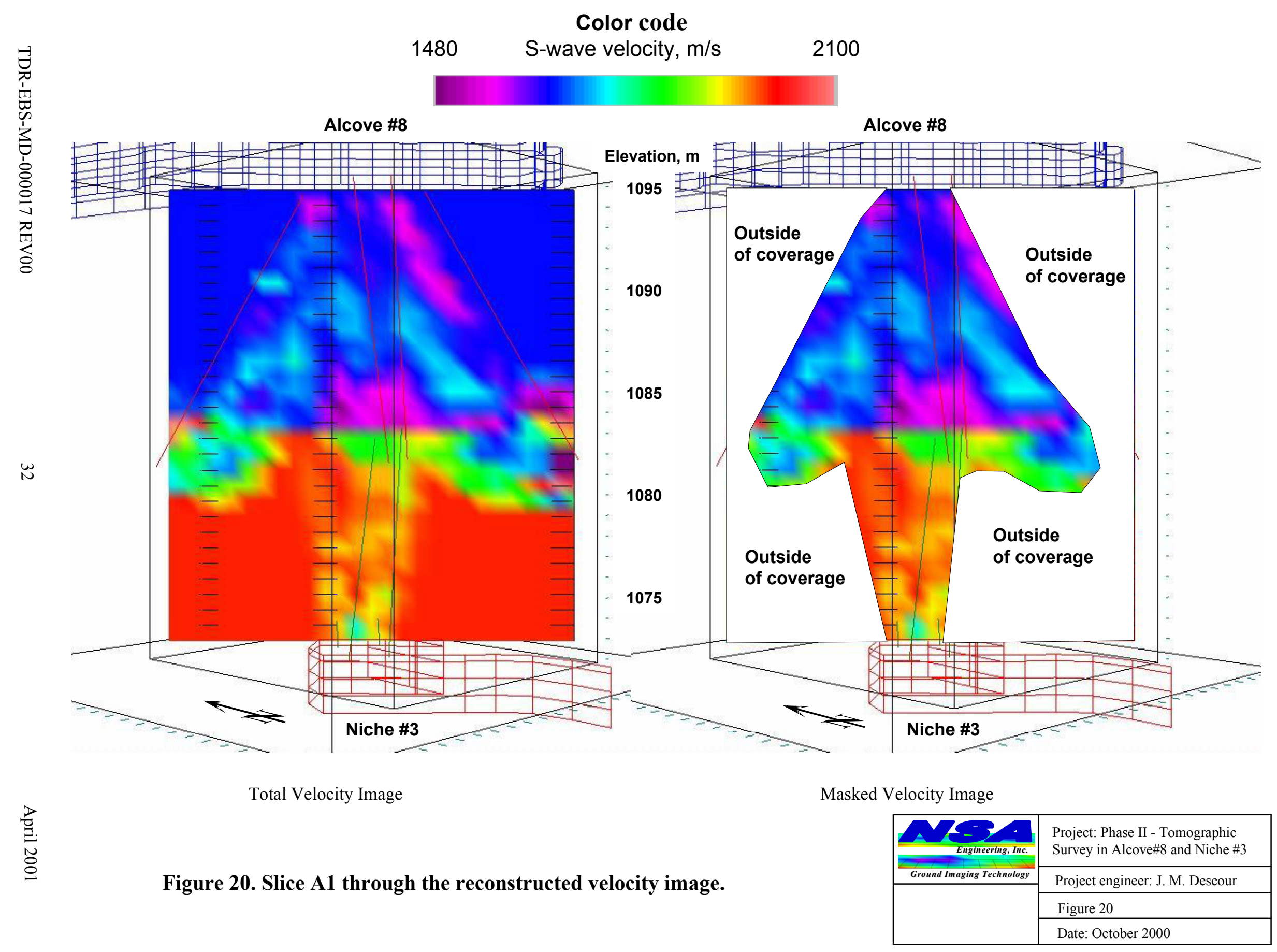




\section{Color code}

$\exists$
0
1
0
0
0
1
$\vdots$
$\vdots$
0
0
0
$\vdots$
0
11
0
8

Alcove \#8

Alcove \#8
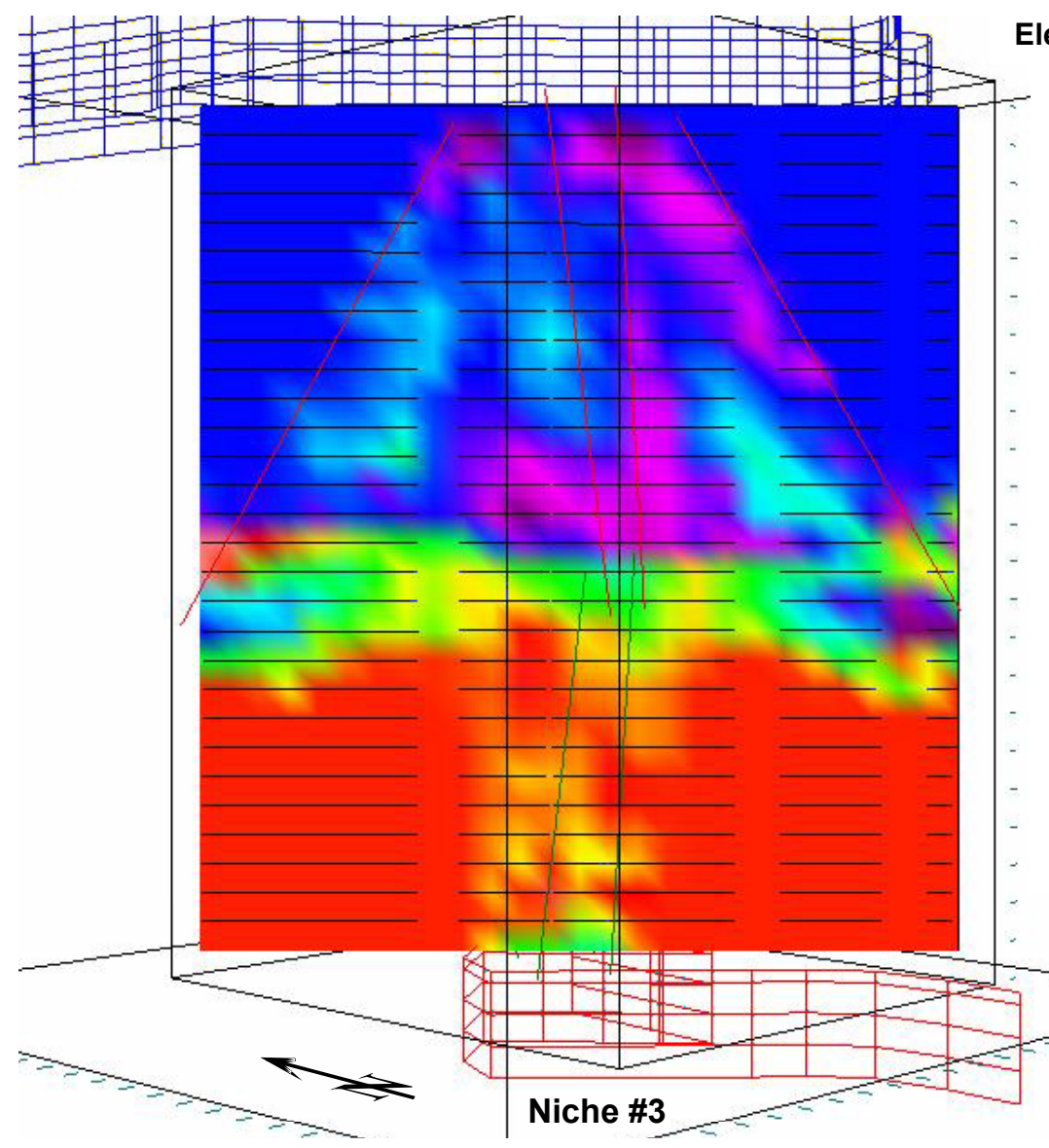

085

$\stackrel{\omega}{\omega}$

Total Velocity Image

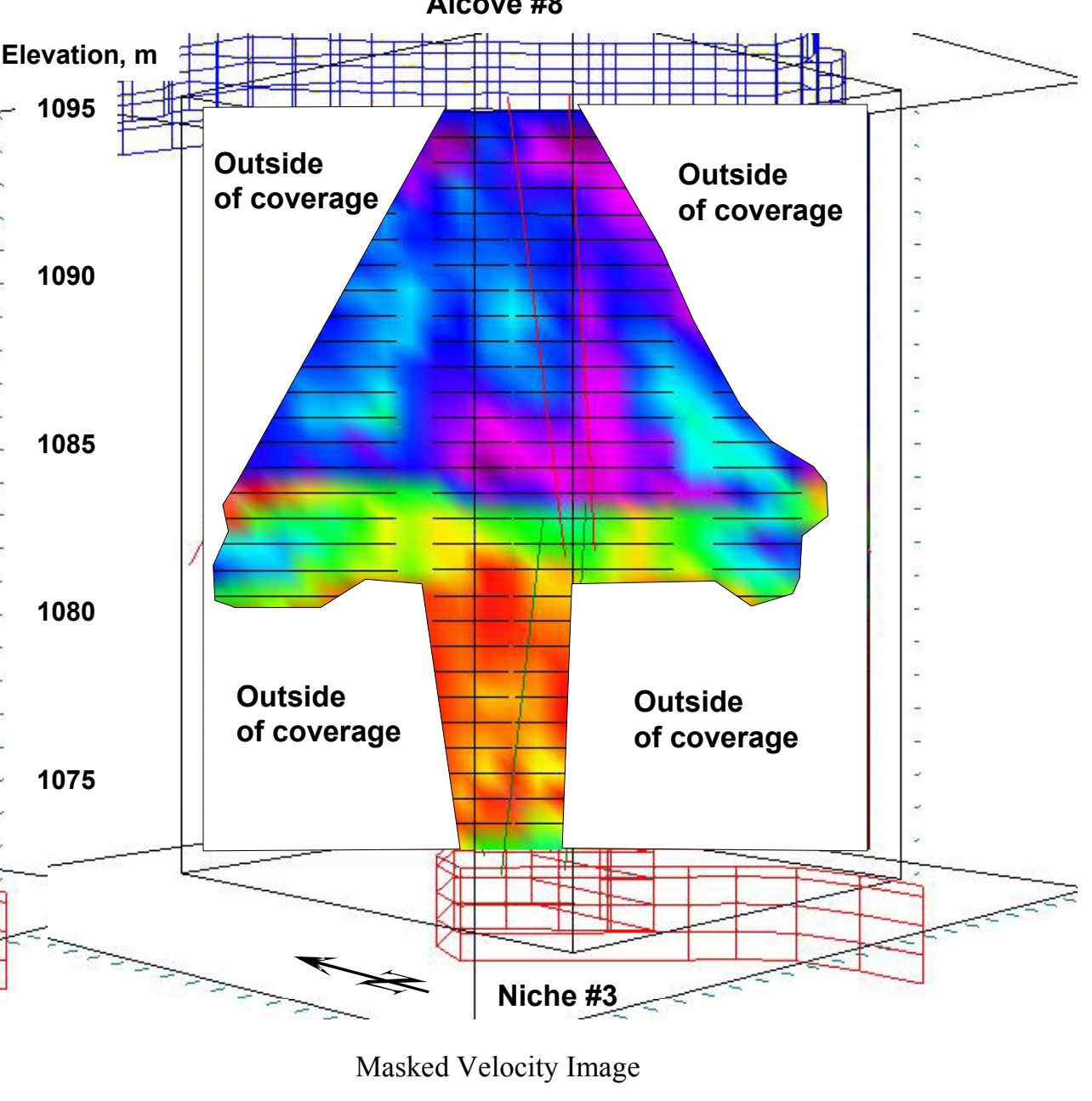

$\frac{1}{0}$
$\frac{0}{8}$
8
0

Figure 21. Slice A2 through the reconstructed velocity image.

\begin{tabular}{|l|l|}
\hline Ground Imaging Technology & $\begin{array}{l}\text { Project: Phase II - Tomographic } \\
\text { Survey in Alcove\#8 and Niche \#3 }\end{array}$ \\
\cline { 1 - 2 } & Project engineer: J. M. Descour \\
\cline { 2 - 2 } & Figure 21 \\
\cline { 2 - 2 } & Date: October 2000 \\
\hline
\end{tabular}




\section{Color code}

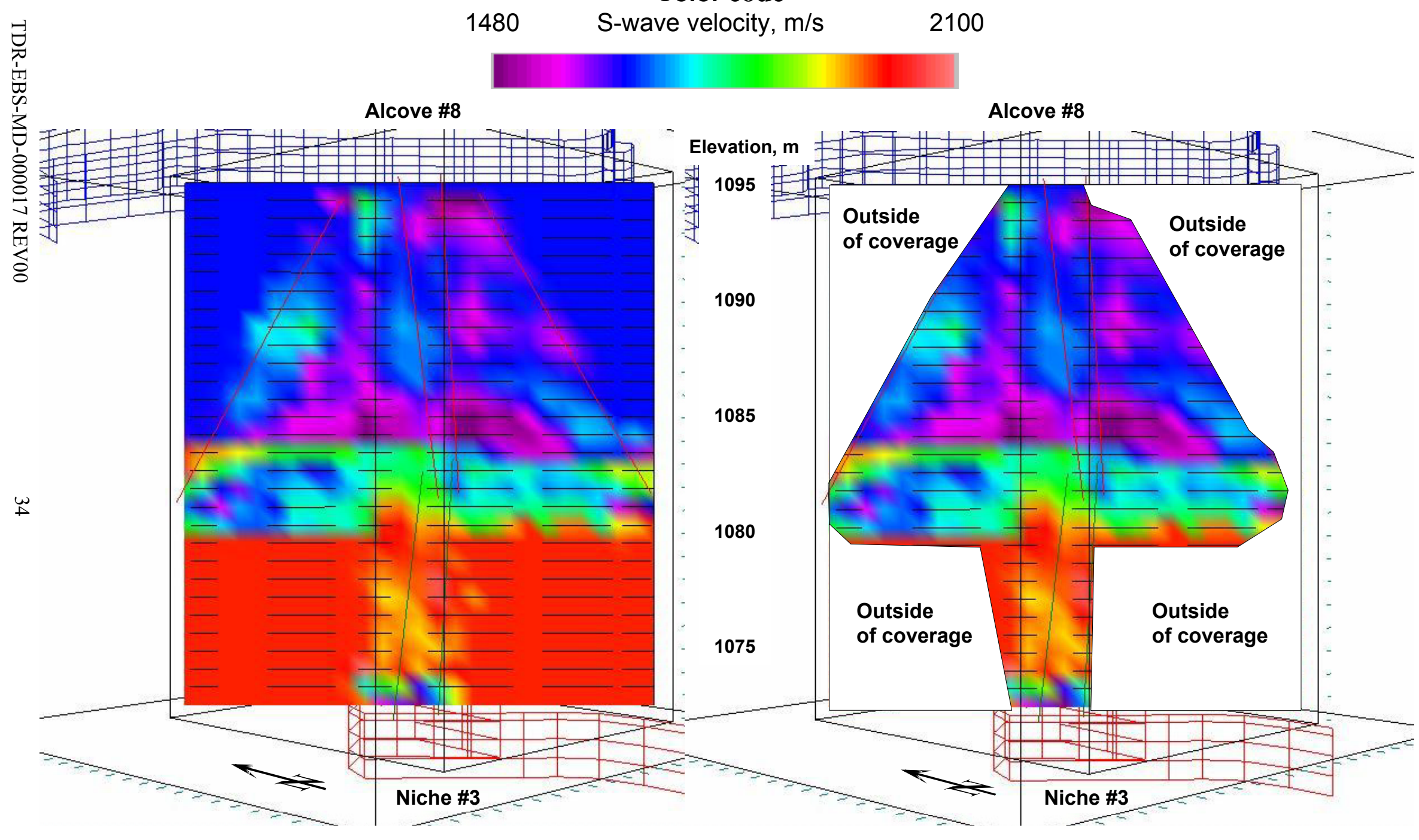

Masked Velocity Image
Total Velocity Image

Figure 22. Slice A3 through the reconstructed velocity image.

\begin{tabular}{|l|l|}
\hline Ground Imaging Technology & $\begin{array}{l}\text { Project: Phase II - Tomographic } \\
\text { Survey in Alcove\#8 and Niche \#3 }\end{array}$ \\
\cline { 2 - 2 } & Project engineer: J. M. Descour \\
\cline { 2 - 2 } & Figure 22 \\
\cline { 2 - 2 } & Date: October 2000 \\
\hline
\end{tabular}




\section{Color code}

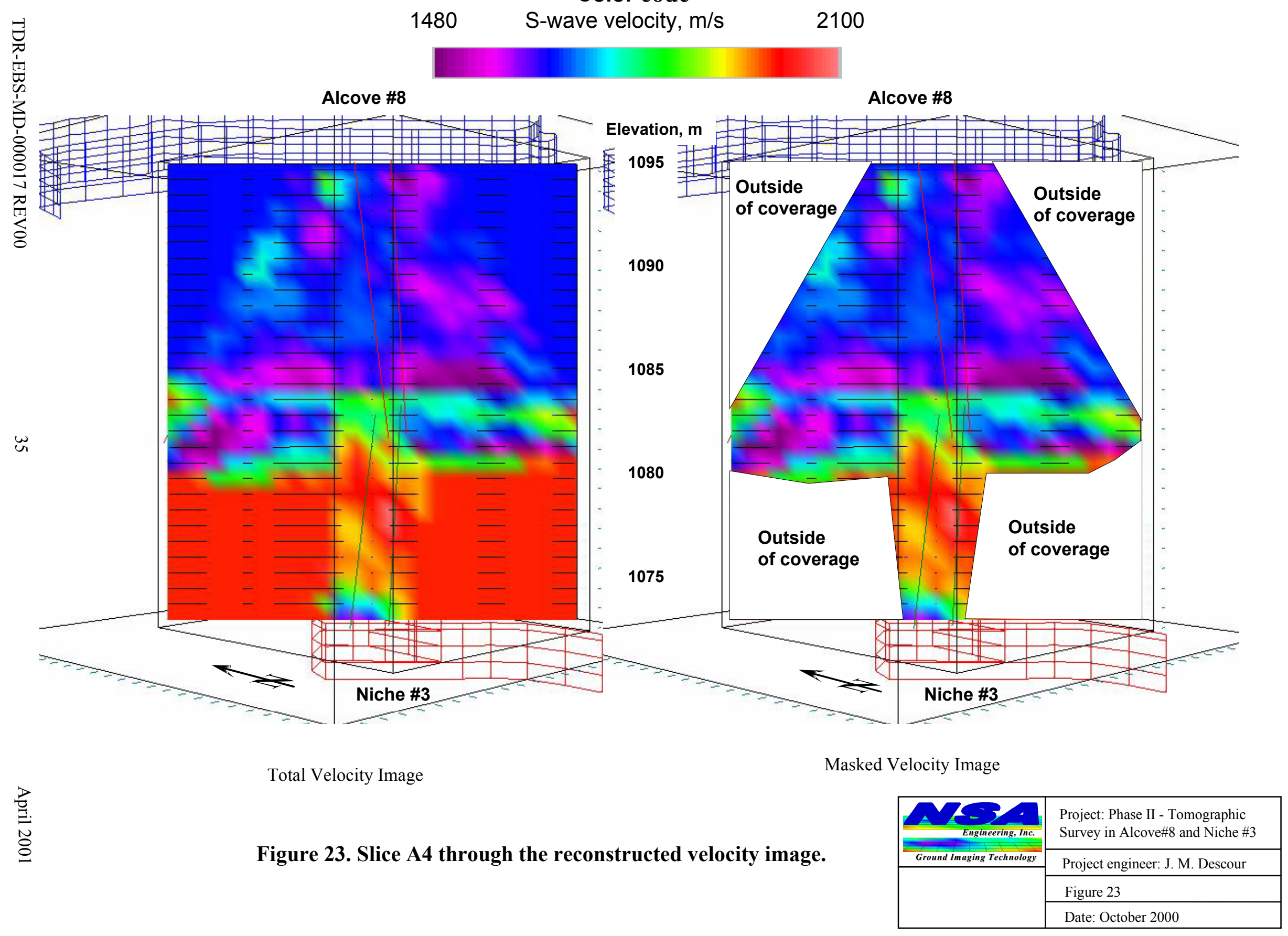




\section{Color code}

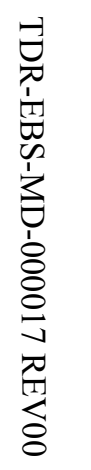

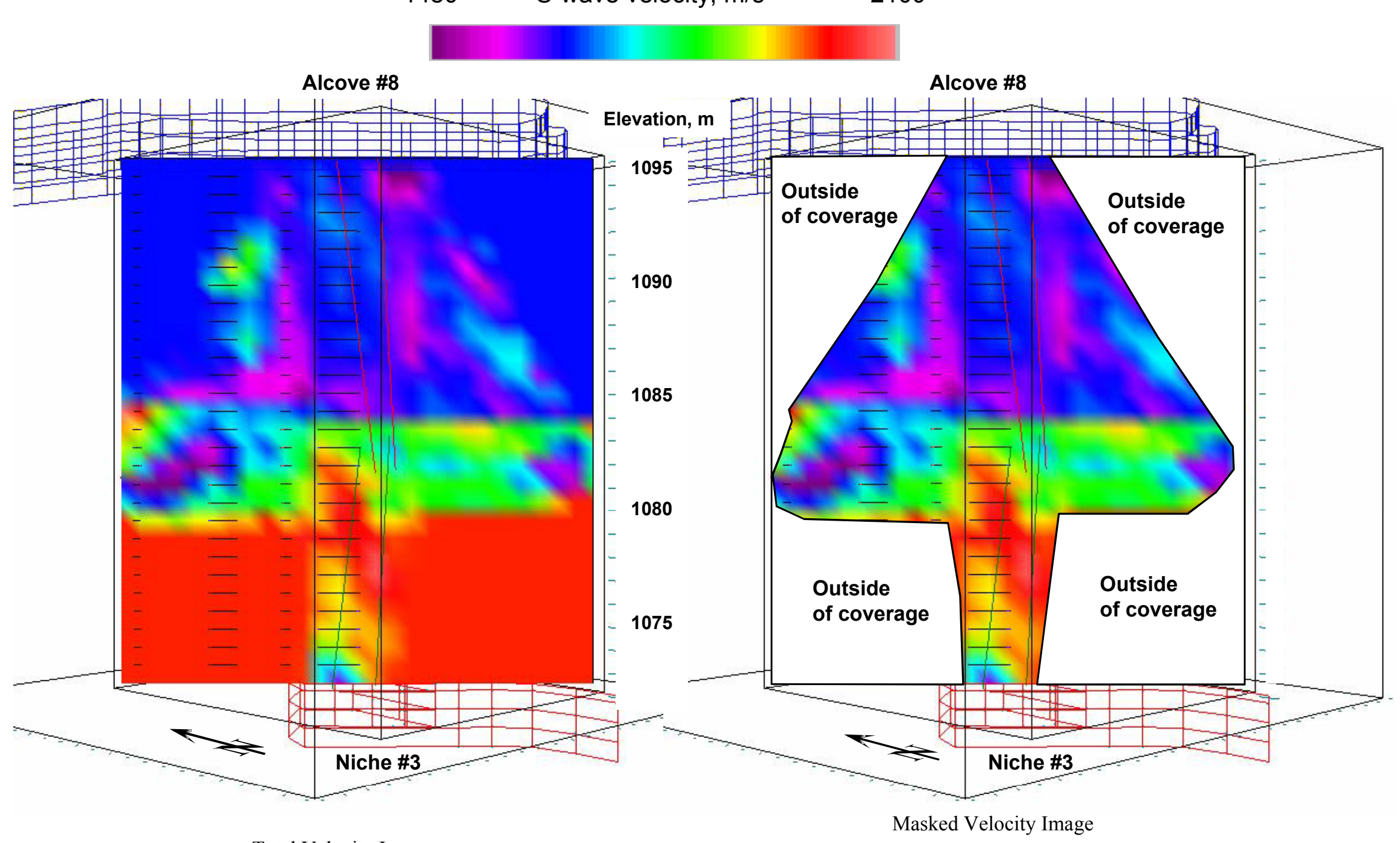

Total Velocity Image

Masked Velocity Image

Figure 24. Slice A5 through the reconstructed velocity image.

\begin{tabular}{|l|l|}
\hline Ground Imaging Technology & Project: Phase II - Tomographic \\
& Survey in Alcove\#8 and Niche \#3 \\
\cline { 2 - 2 } & Project engineer: J. M. Descour \\
\cline { 2 - 2 } & Figure 24 \\
\cline { 2 - 2 } & Date: October 2000 \\
\hline
\end{tabular}




\section{Color code}

$\exists$
0
1
0
0
0
1
$\vdots$
$\vdots$
0
0
0
$\vdots$
0
11
0
8

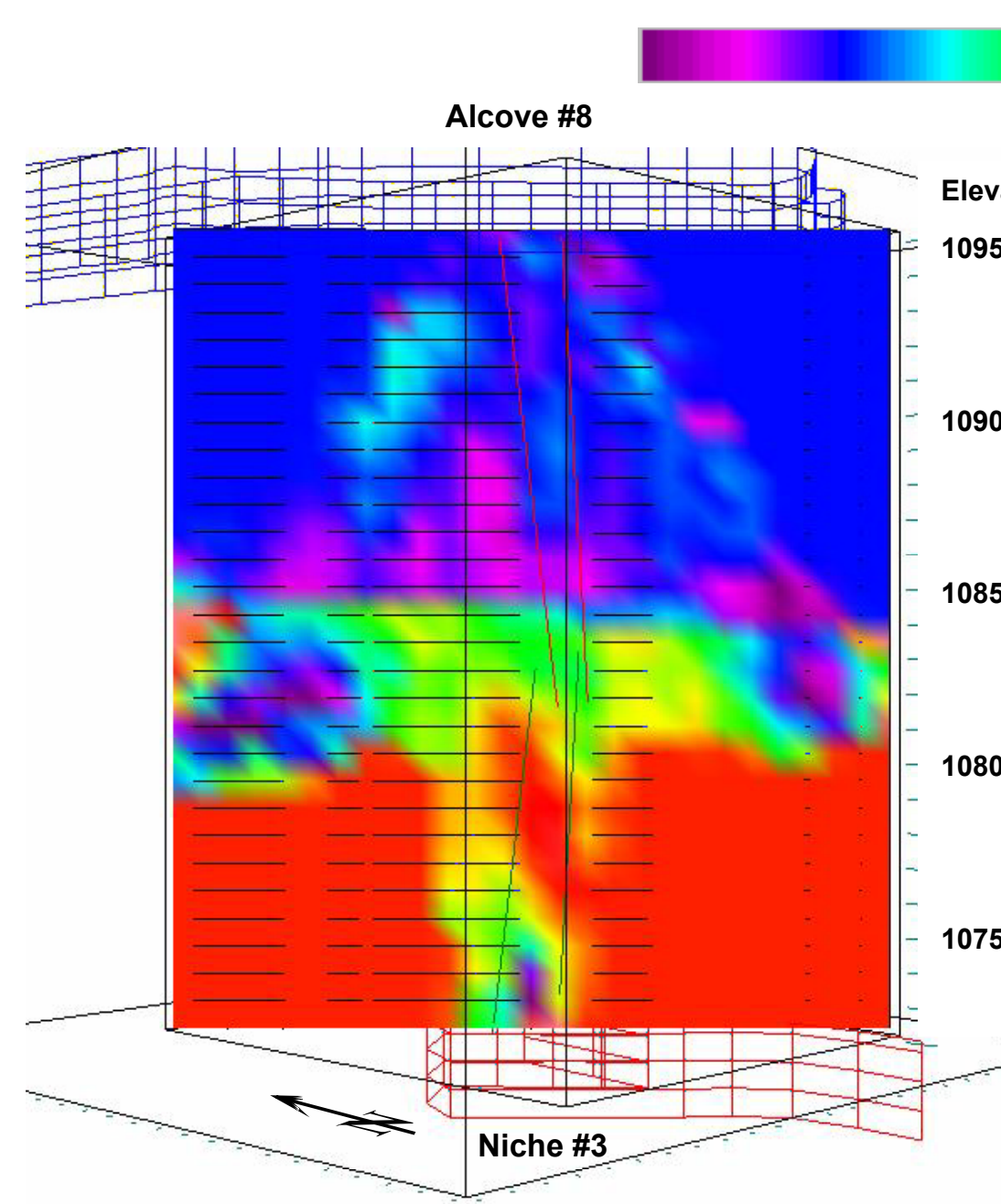

Total Velocity Image

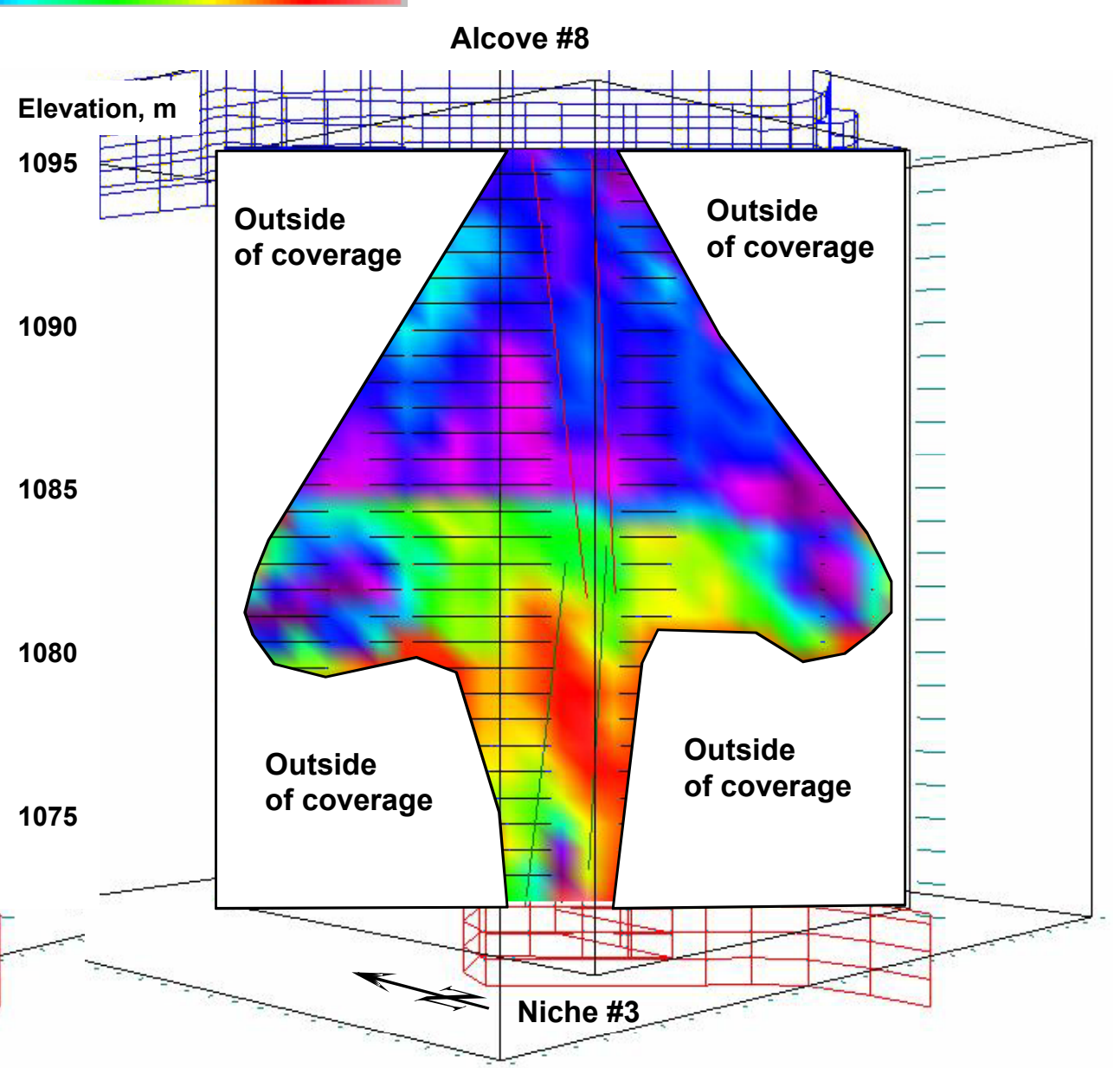

Masked Velocity Image

Figure 25. Slice A6 through the reconstructed velocity image.

\begin{tabular}{|c|l|}
\hline Eround Imaging Technology & Project: Phase II - Tomographic \\
\cline { 1 - 2 } & Survey in Alcove\#8 and Niche \#3 \\
\cline { 2 - 2 } & Figure 25 engineer: J. M. Descour \\
\cline { 2 - 2 } & Date: October 2000 \\
\hline
\end{tabular}




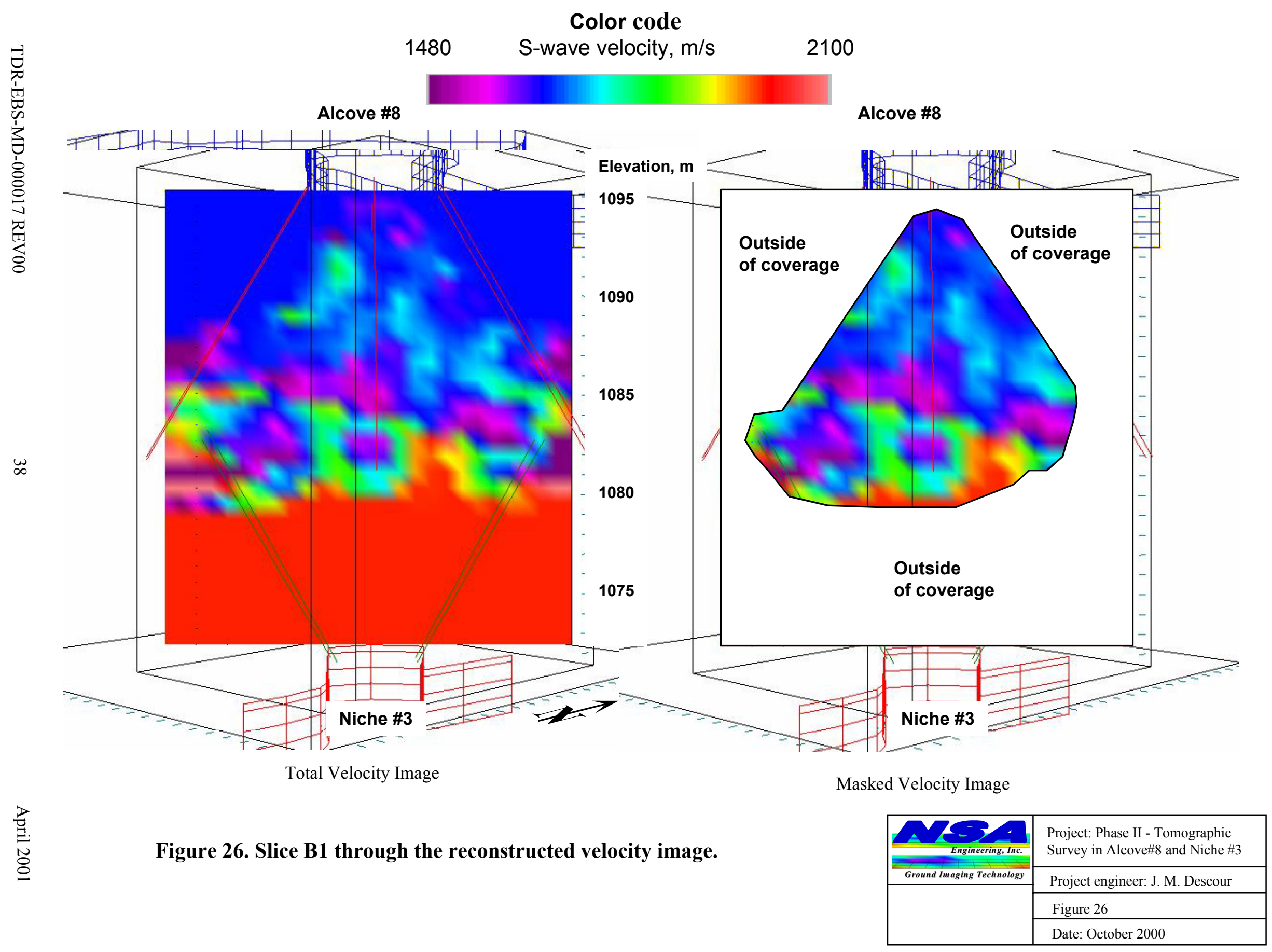




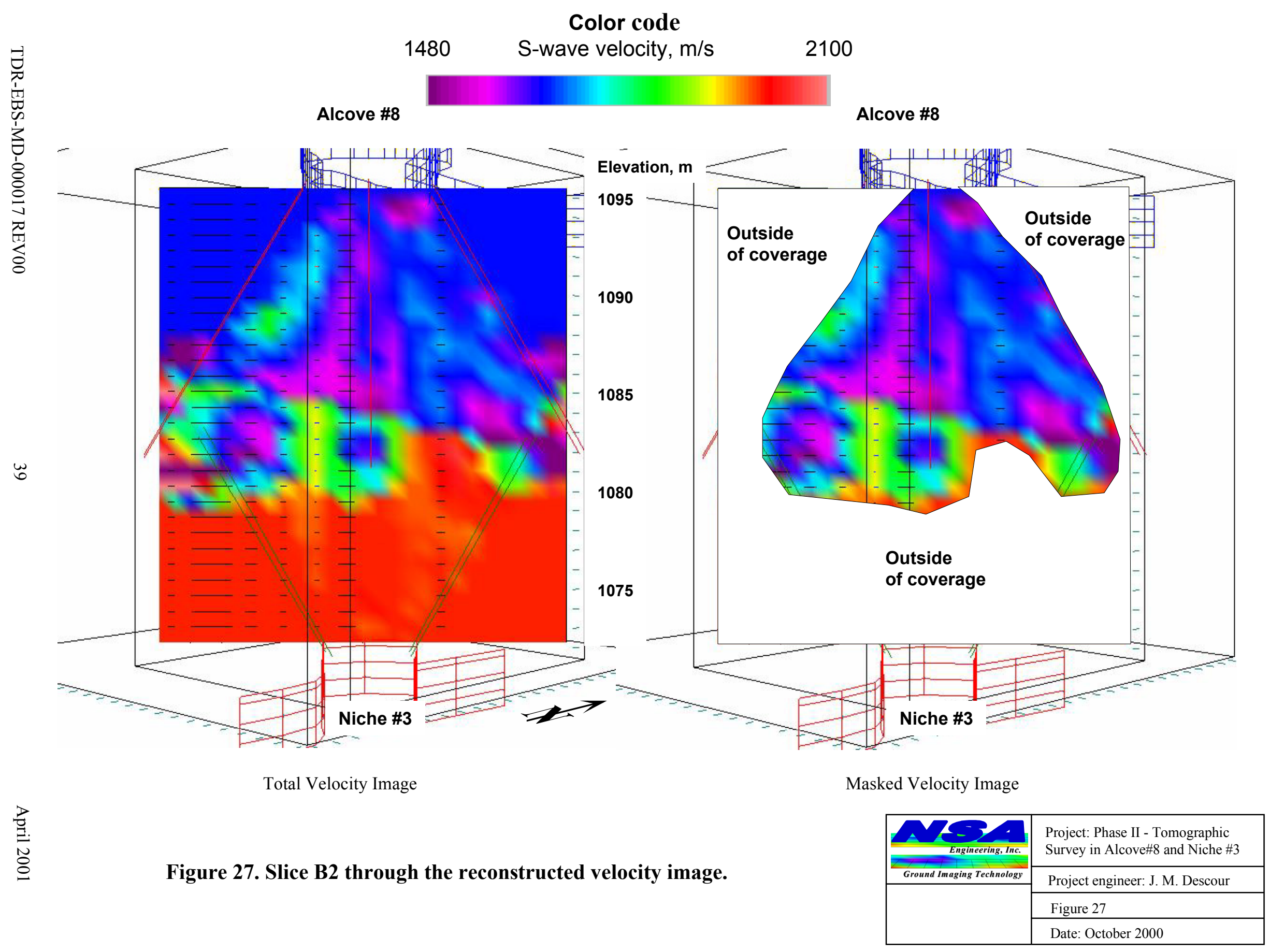




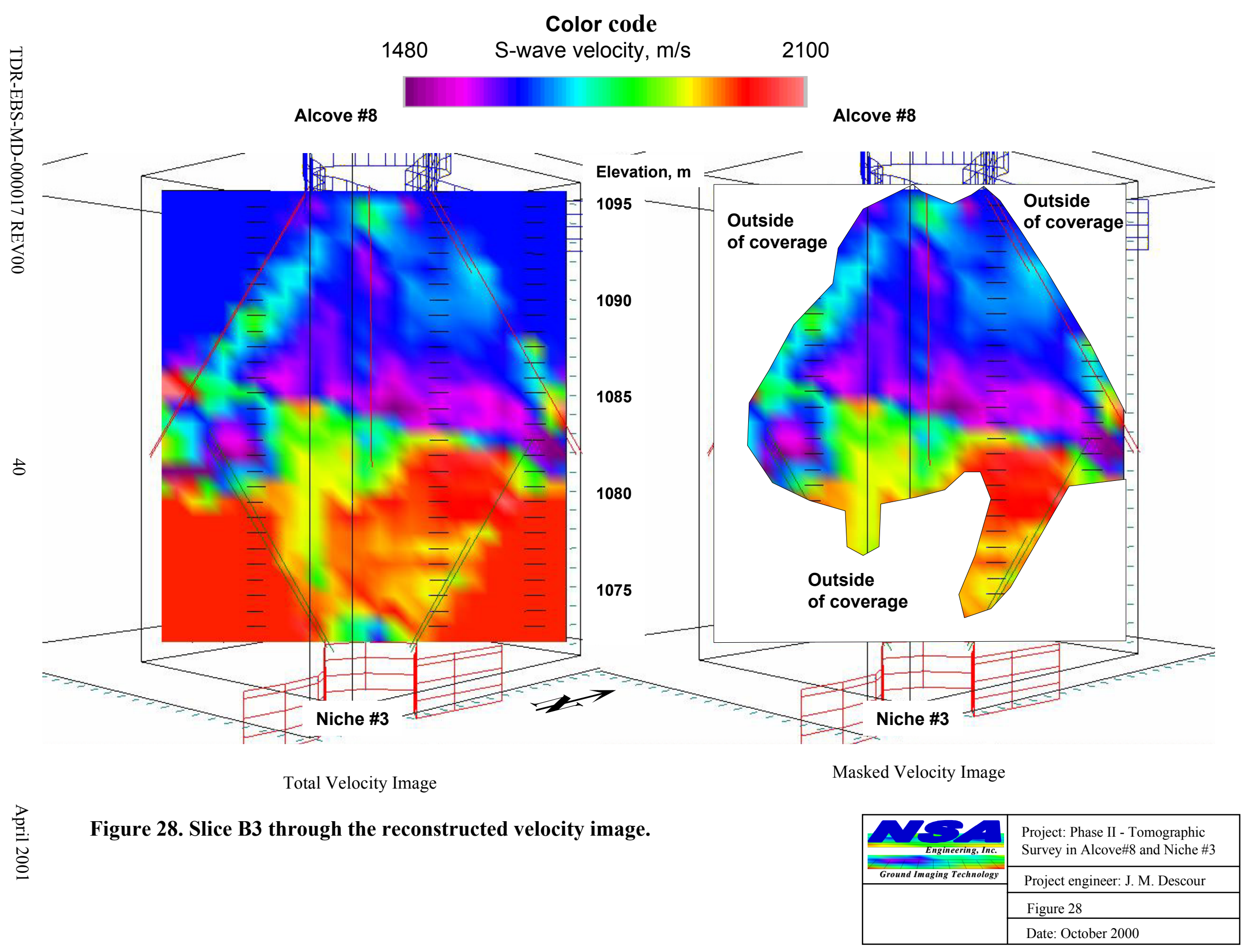




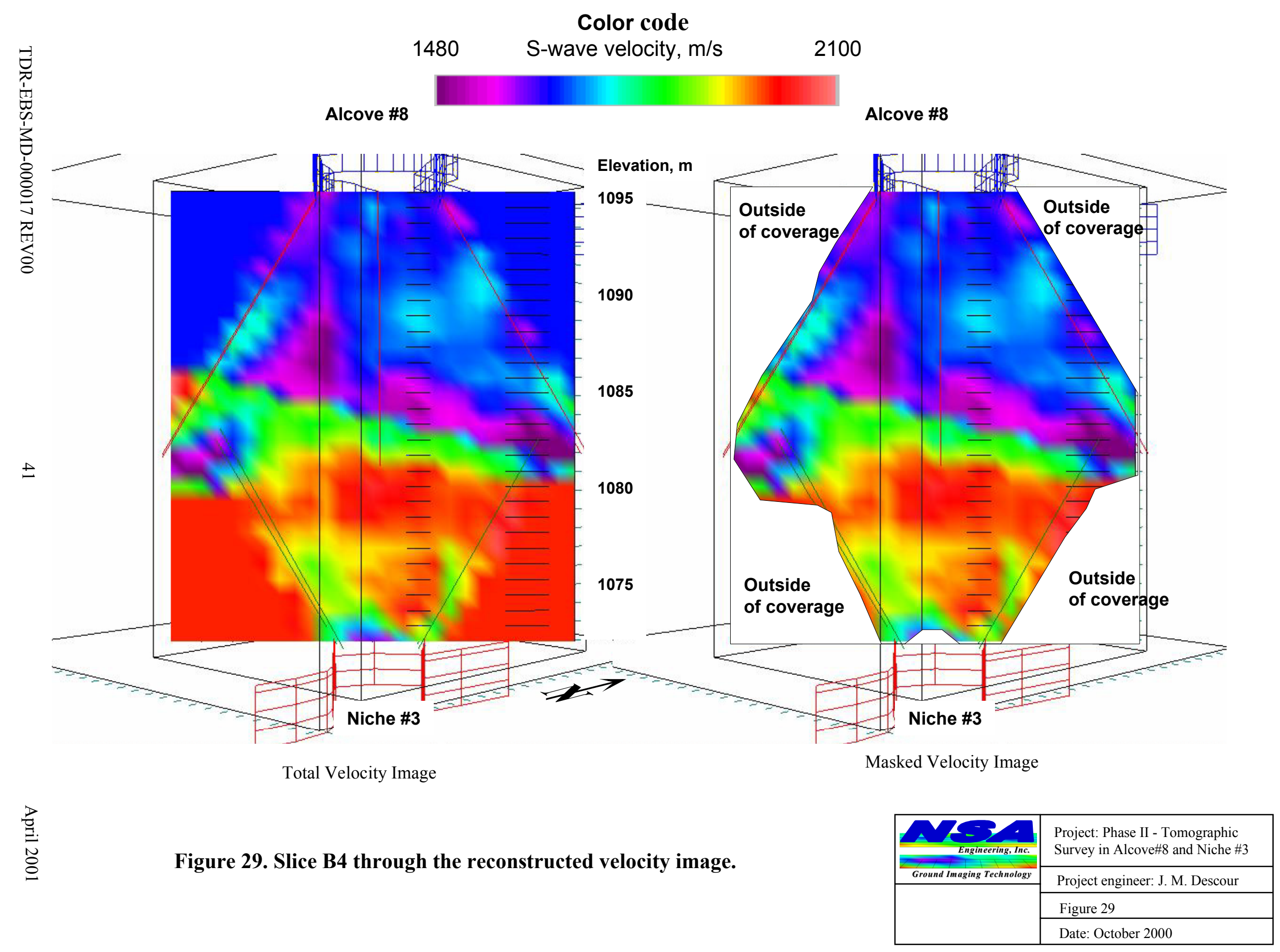




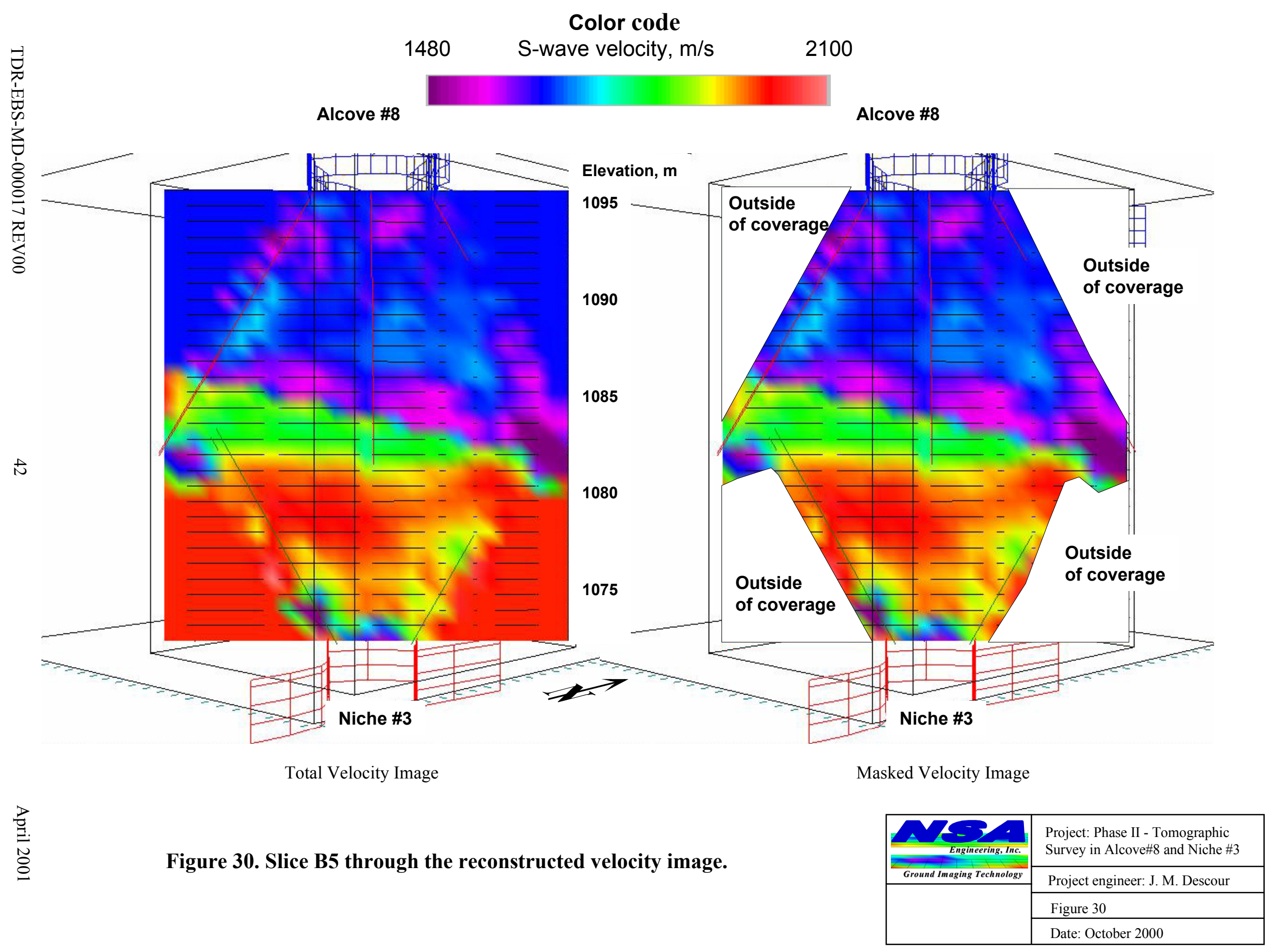




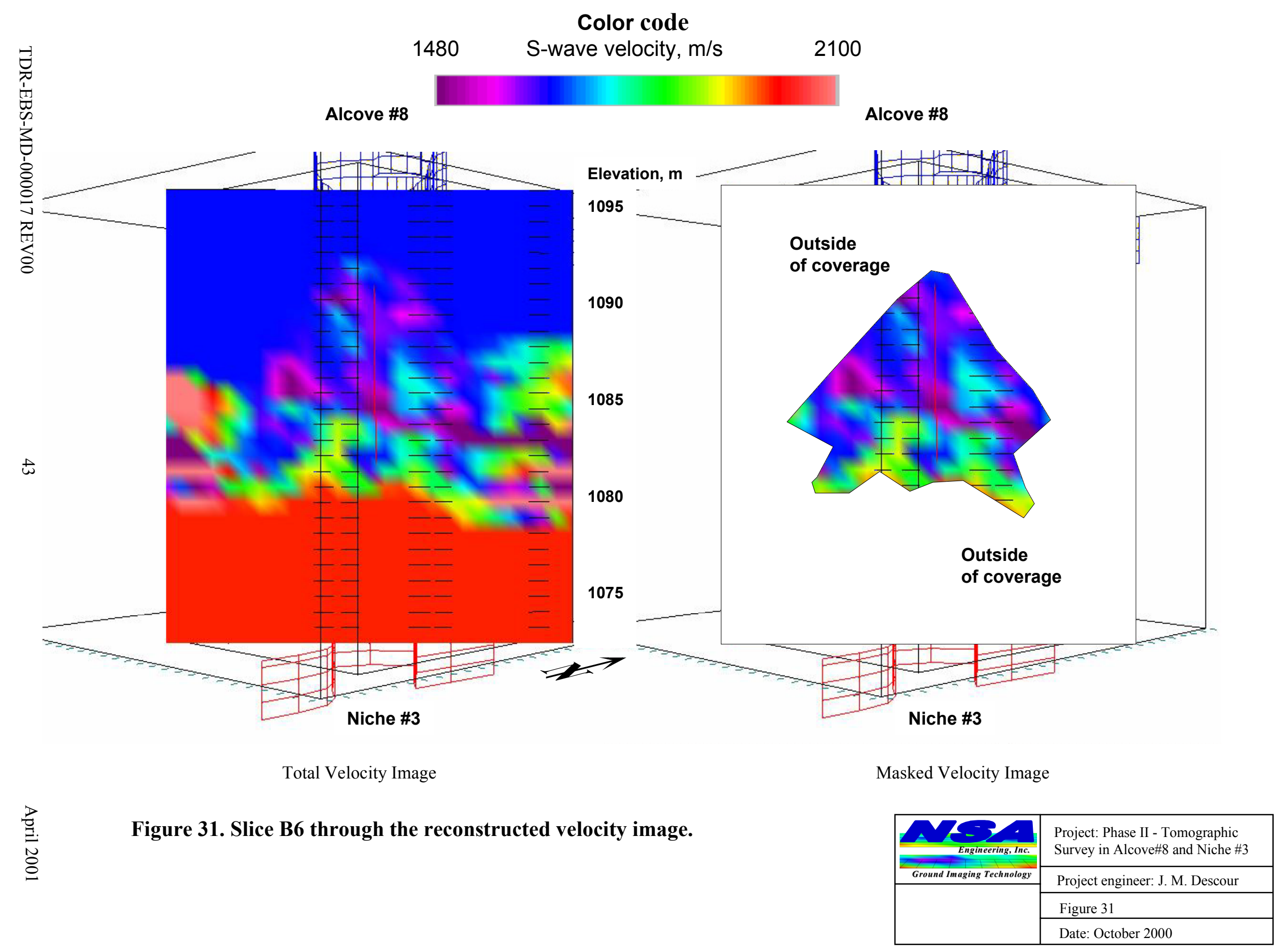




\section{Color code}

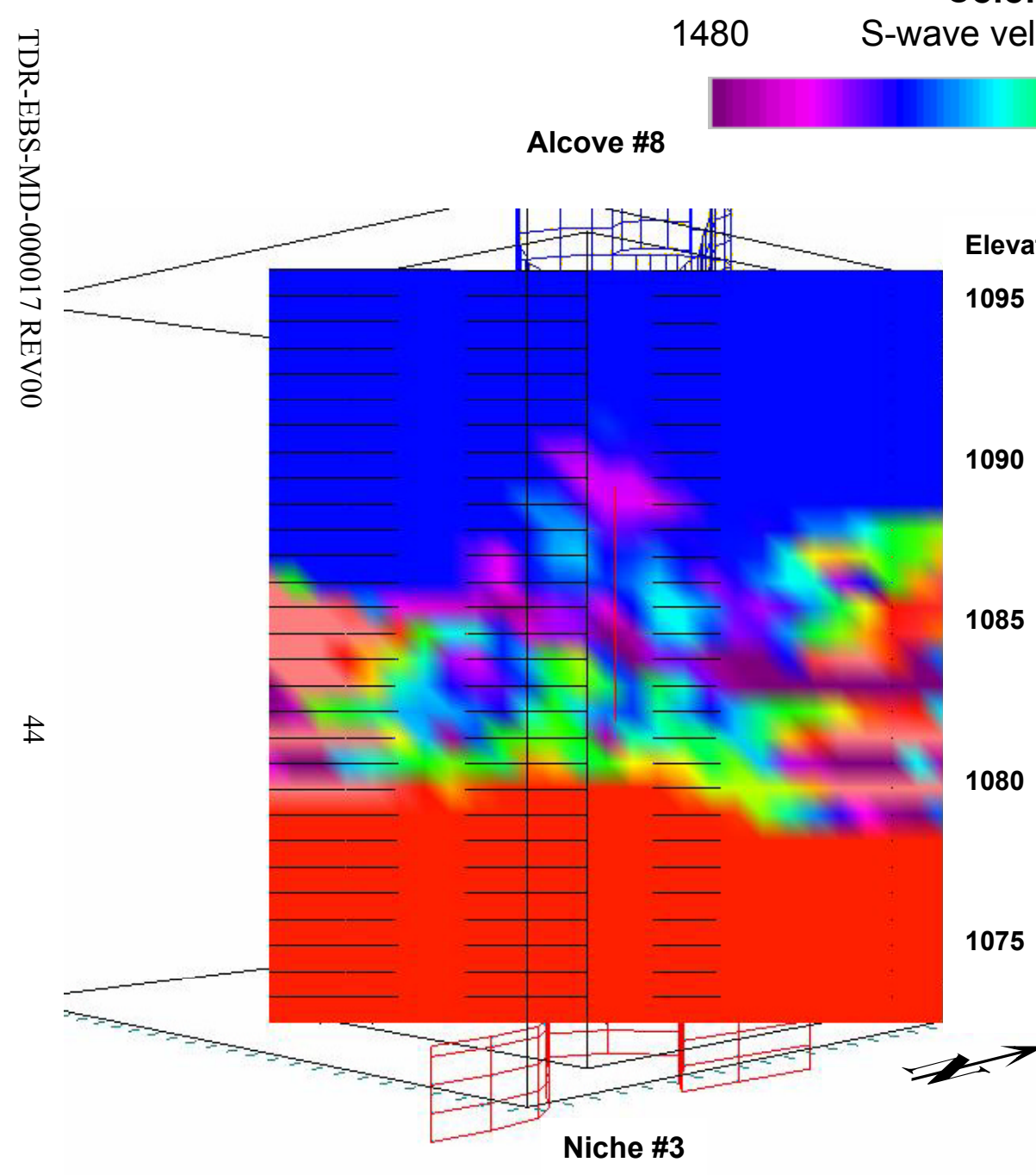

Total Velocity Image

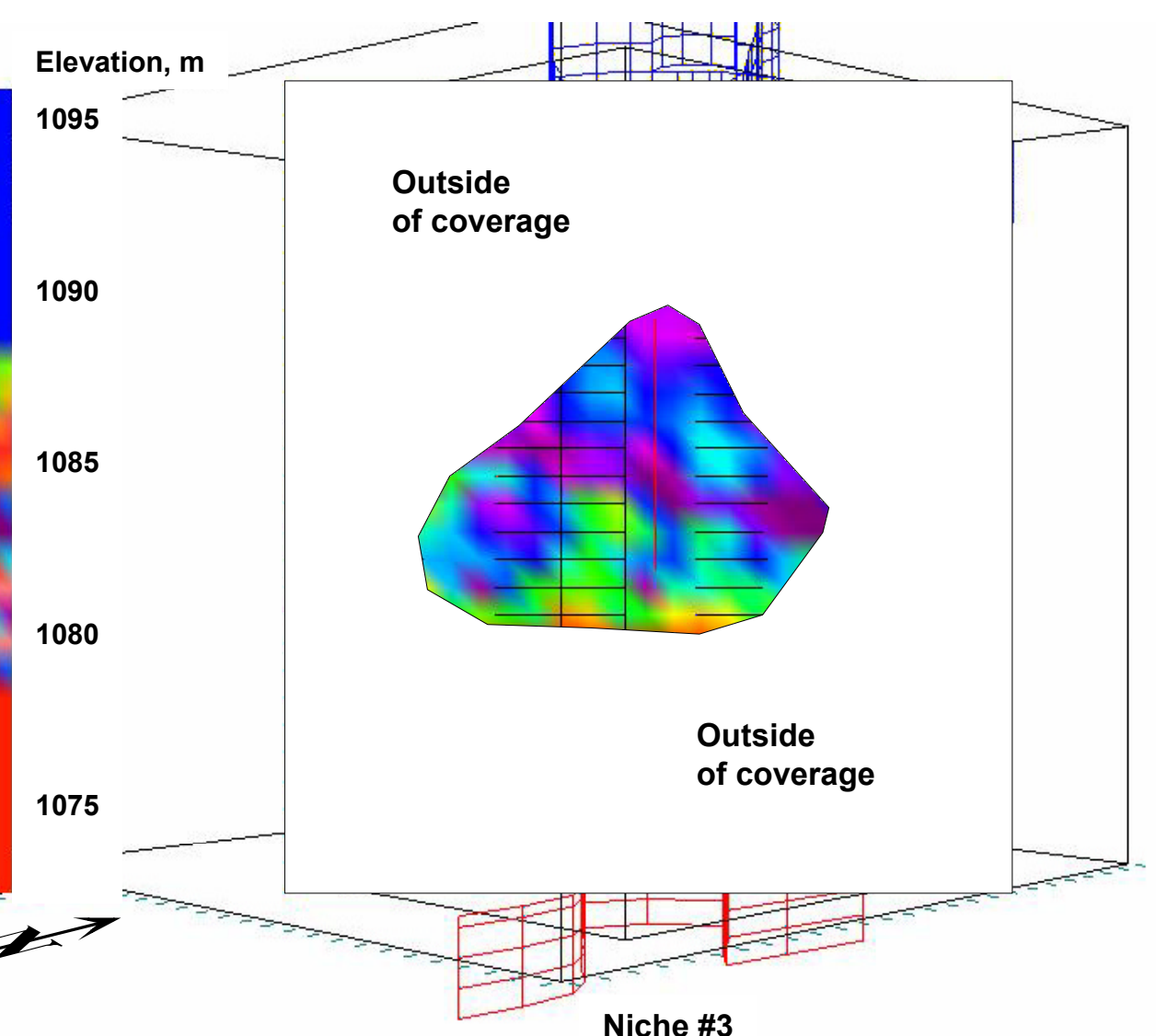

\section{Niche \#3}

Masked Velocity Image

\begin{tabular}{|l|l|}
\hline Ground Imaging Technology & Project: Phase II - Tomographic \\
\cline { 1 - 2 } & Survey in Alcove\#8 and Niche \#3 \\
\cline { 2 - 2 } & Project engineer: J. M. Descour \\
\cline { 2 - 2 } & Figure 32 \\
\cline { 2 - 2 } & Date: October 2000 \\
\hline
\end{tabular}




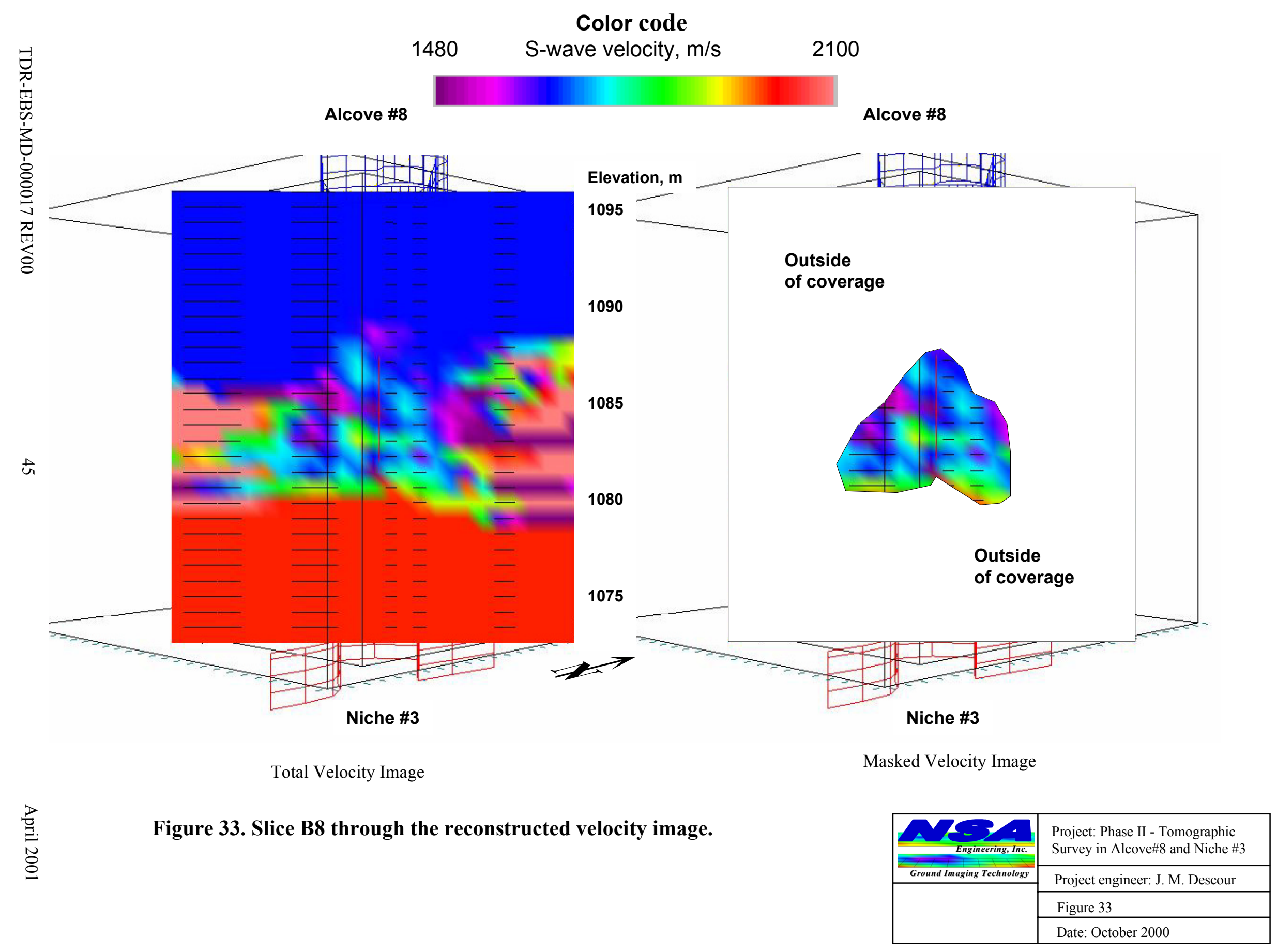




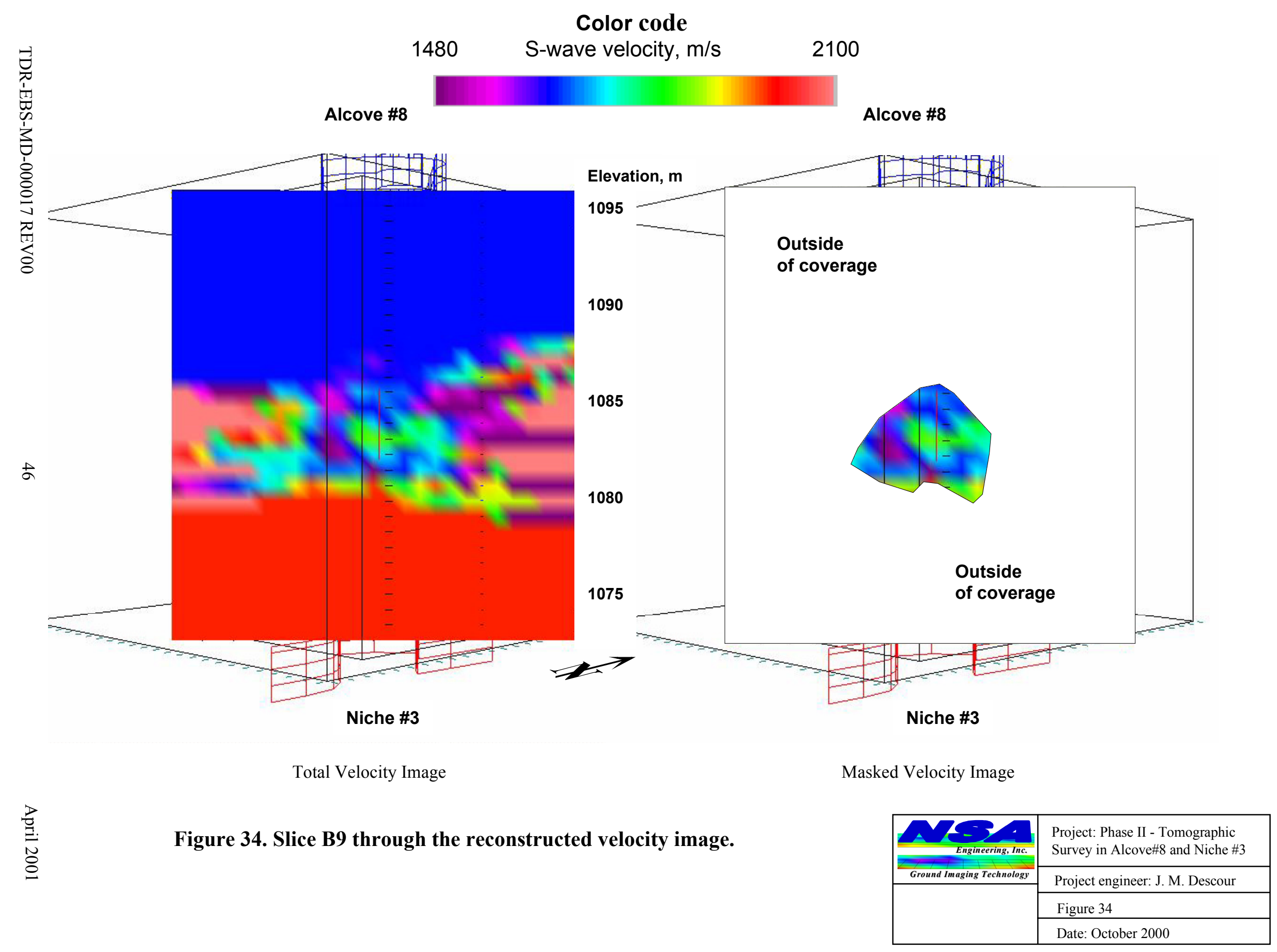




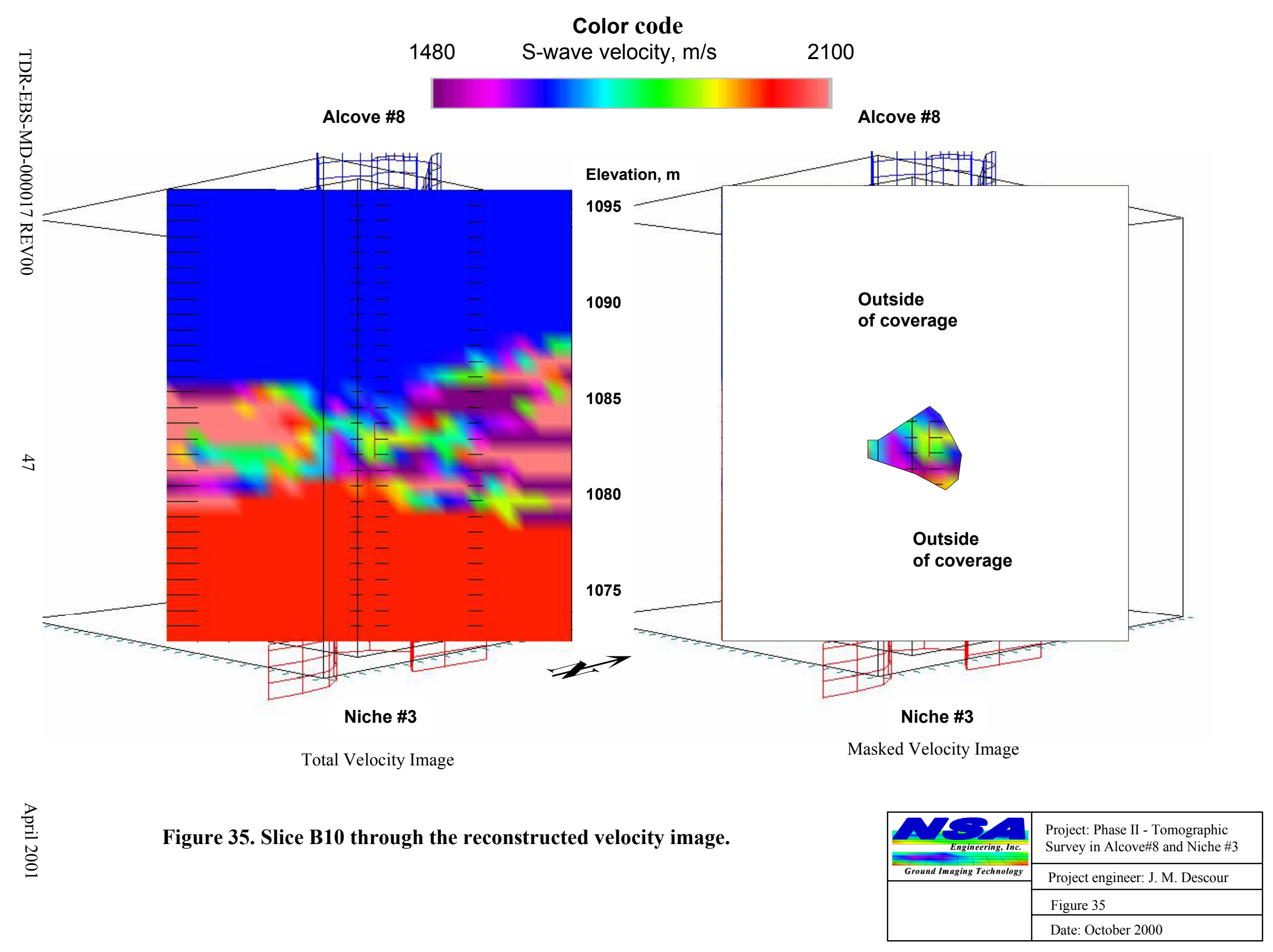


APPENDIX A

ELECTRONIC COPY OF DATA 


\section{INTENTIONALLY LEFT BLANK}


ELECTRONIC COPY OF DATA 